Sessions d'étude - Société canadienne d'histoire de l'Église catholique

\title{
Quelques aspects de l'oeuvre de Paul Benoît au Nouveau Monde, 1891-1915
}

\section{Maurice Dupasquier}

Volume 37, 1970

La vie religieuse au Manitoba

URI : https://id.erudit.org/iderudit/1007279ar

DOI : https://doi.org/10.7202/1007279ar

Aller au sommaire du numéro

Éditeur(s)

Les Éditions Historia Ecclesiæ Catholicæ Canadensis Inc.

ISSN

0318-6172 (imprimé)

1927-7067 (numérique)

Découvrir la revue

Citer cet article

Dupasquier, M. (1970). Quelques aspects de l'oeuvre de Paul Benoît au Nouveau Monde, 1891-1915. Sessions d'étude - Société canadienne d'histoire de l'Église catholique, 37, 111-144. https://doi.org/10.7202/1007279ar

Tous droits réservés @ Les Éditions Historia Ecclesiæ Catholicæ Canadensis Inc., 1972
Ce document est protégé par la loi sur le droit d'auteur. L'utilisation des services d'Érudit (y compris la reproduction) est assujettie à sa politique d'utilisation que vous pouvez consulter en ligne.

https://apropos.erudit.org/fr/usagers/politique-dutilisation/ 


\section{Quelques aspects de l'œuvre de Paul Benoît au Nouveau Monde, 1891-1915}

Au commencement était le chaos.

Puis quarante rois constituèrent et défendirent l'univers: la France. (Il est vrai qu'un roi maladif dut s'appuyer quelque peu sur une sainte paysanne.) Le temps de leur puissance fût un âge d'or. Tous les influents tiraient des revenus satisfaisants de leurs terres; tous les autres savaicnt quelle ćtait leur place. La sainte Église bénissait cet ćtat de choses sur la terre et détenait les clés du royaume des cieux. Sa majesté très chrétienne gardait la France au premier rang de l'Europe, tout en laissant la noblesse, les provinces et les parlements agir à leur guise. Les arts et les lettres françaises étaient florissants et faisaient l'envie du monde entier.

Mais les forces du chaos réapparurent à travers le " reptile "Voltaire. - l'infernal » Rousseau, et dans la plus monstrueuse des sociétés, la maçonnerie. Ces puissances anéantirent l'univers dans cette année épouvantable: 1789. Pendant vingt-cinq ans la France restera dans le chaos. Puis, provisoirement, l'univers sera rétabli. Mais, après 1830, la France sombrait une nouvelle fois dans le cataclysme.

Tous ceux qui croient à la vraie France doivent maintenant s'unir pour conjurer les forces du mal, et pour rétablir l'univers.

Voilà ce que pensait nombre de Français conservateurs et royalistes au temps de Paul Benoît. C'est, affirme Edward R. Tannenbaum, le

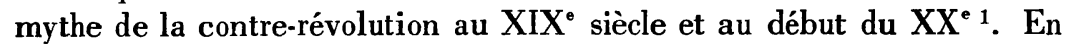
gros, tel était aussi le sentiment fondamental de Paul Benoît à l'égard de l'histoire de France: huit siècles glorieux du règne débonnaire des Capétiens, des Valois et des Bourbons; l'apogée de la France royale sous Louis IX, l'homme aux Croisades et à la réputation de sagesse et de sainteté; le "noble royaume" sous la tutelle de sa "noble famille" et en harmonie avec le père commun de tous les fidèles; tout cela ruiné en un seul jour par le " martyre " de Louis XVI, à la " grande réputation de vertu ", et par la chute de la monarchie française !

1 Dans Ideas in History, Durham, Duke University Press, 1965. 
On ne comprendrait pas la mentalité de Benoît, son opposition irréductible et permanente aux philosophes, aux libéraux, aux juifs, aux francs-maçons, à tous les partisans des idées modernes, si on ne tenait compte du fait que, pour lui, c'était "au nom de la liberté " qu'ils avaient détruit "l'ancienne monarchie chrétienne, le plus populaire des gouvernements qui ait jamais existé sur la terre ${ }^{2}$ ".

A " la fille aînée de l'Église " accomplissant les œuvres de Dieu depuis le baptême de Clovis, avait succédé, ce jour-là, sous l'impulsion de quelques "grands hâbleurs et petits faiseurs", et au moyen de la Révolution française, - cette "fille sortie de l'enfer ", - la nation française divisée par les "mortels principes de 89 ", affaiblie, en proie au mal comme pouvait l'être le corps humain dévoré par un chancre. Aberration inexplicable d'un peuple refoulé ?

Aberration, certes. Inexplicable, non. Les derniers rois de France, en trempant dans le gallicanisme, avaient quelque peu dévié, avec la " complicité " du peuple et des évêques du royaume, de la mission providentielle de la nation française: être le bras droit du représentant de Dieu sur la terre, accomplir les œuvres de Dieu. La Providence avait donc permis que la "noble famille" et le "noble royaume" fussent châtiés à cause de cet égarement passager. Dieu pouvait permettre le mal, mais non pas l'accomplir lui-même, cela va de soi. $\mathrm{La}$ désolation était donc survenue par personne interposée. De sorte que la Révolution française était une œuvre néfaste permise par Dieu mais accomplie par les forces du mal poursuivant leurs desseins sataniques depuis l'introduction du péché originel dans le monde.

Le diable et ses acolytes pouvaient revêtir maintes défroques. En réalité, la Révolution française, c'était une vaste * conspiration maçonnique dont 1789 fut l'explosion", comme devait l'exprimer Louis Hacault, son voisin dans la montagne de Pembina, grand opposant de la maçonnerie et de toutes ses œuvres, comme l'était également Benoît.

Or, Paul Benoît descendait d'une longue lignée attachée à la glèbe dans la Franche-Comté. Sa famille représentait la France rurale et terrienne, conservatrice et catholique, royaliste intransigeante par surcroît, comme il l'a lui-même fait entendre ${ }^{3}$. Les traditions y étaient à l'honneur, les innovations pour le moins suspectes. Ses aïeux étaient restés franchement attachés à leurs rois, bien qu'aucun n'eût tenu un poste auprès d'eux. Chaque jour son père lisait les Écritures. Le jeune homme subissait une forte influence familiale. Aussi n'est-il pas étonnant

2 Paul Benoît, «Quelques notes historiques sur les quatre ou cinq phases du libéralisme en France , dans Le Mouvement catholique, V, 24 [lire 10] (1900), p. 253-256.

3 Paul Benoît, Mon roi ", dans Le Manitoba, XXVIII, 2 (30 novembre 1898), 2; XXVIII, 3 (7 décembre 1898), 2; XXVIII, 4 (14 décembre 1898), 2. 
que Paul Benoît ait bientôt songé à la vie ecclésiastique, et, dès l'âge de seize ans, à la vie commune, peut-être canonique ${ }^{4}$.

Étudiant ecclésiastique à Rome, puis jeune prêtre, puis directeur de séminaire, Paul Benoît qui dès sa jeunesse connaissait dom Gréa avait été attiré par la personnalité et les idées de celui-ci. Cela était d'autant moins surprenant que d'autres influences durant ses années d'études s'étaient conjuguées pour le confirmer dans ses idées conservatrices, royalistes et ultramontaines ${ }^{5}$ et accentuer à ses yeux l'attrait du passé, des "beaux siècles» pour lesquels il avait une nette prédilection au prime abord. Il avait été admis dans la congrégation des Chanoines réguliers de l'Immaculée Conception, en 1877, où l'on se défendait bien, à l'instar du restaurateur de ce genre de vie, d'avoir créé quoi que ce fût qui ne se trouvait déjà dans le passé, dans la tradition religieuse occidentale. C'était au contraire la restauration de l'antique vie canonique exercée généralement par le clergé des premiers siècles.

Très tôt dom Benoît avait pris de l'ascendant auprès de dom Gréa. Bien qu'il ne fût pas l'un des membres primitifs de la congrégation, il était vite devenu le bras droit du fondateur, l'un et l'autre étant largement axés sur le passé et ayant des idées à peu près totalement en harmonie.

Ces années passées à Saint-Claude, au berceau jurassien de la congrégation, devaient être parmi les plus productives de toute sa vie. Dans les quinze années précédant son départ pour le Nouveau Monde, Benoît avait rédigé autant de volumes ${ }^{6}$.

Clergé apostolique, et non hiérarchique, régulier et non séculier, les Chanoines réguliers de l'Immaculée Conception devaient remplir dans tous les territoires qui leur seraient confiés le même rôle que ne l'eussent fait des curés ordinaires. En plus, cependant, ils vivaient leur vie religieuse, commune, axée sur la liturgie d'abord, sur les pratiques pénitentielles ensuite. On le voit, il ne s'agissait pas de moines.

Même dans sa congrégation, destinée au reste à exercer ses fonctions au sein des paroisses, dom Benoît ne devait pas vivre à l'écart du monde, comme le faisaient les moines. Au contraire, par la nature même de son

4 Sur la jeunesse de Paul Benoît, cf. une notice du père Bernard Berthet, dans les Mémoires de la Société d'émulation du Jura, 194.7.

5 Paul Benô̂t, «on roi * (2), dans Le Manitoba, XXVIII, 3 (7 décembre 1898), 2.

6 La vérité sur Voltaire, 1877; La cité antichrétienne au XIXं siècle, 18851886, quatre volumes; Histoire de l'abbaye et de la terre de Saint-Claude, 1890 et 1892, deux volumes; et le manuscrit primitif de La Vie des Clercs dans les Siècles passés, détruit en 1891 et qui était, disait-il, l'équivalent de sept ou huit volumes, bien qu'il ne fût pas rédigé dans sa forme définitive. L'avant-dernier ouvrage n'avait reçu, à Notre-Dame-de-Lourdes, que les retouches finales du second volume. 
affiliation religieuse, il restait en contact avec les populations au service desquelles il était affecté. De sorte que, pour lui, la France ne pouvait pas ne pas être présente à chaque jour de sa vie.

L'État républicain sorti du Siècle des lumières s'était présenté, à l'orée de la carrière de Paul Benoît et à la suite des incidents de la Commune, sous la défroque de la Troisième République. Celui qui redoutait et détestait la maçonnerie suffisamment pour lui consacrer deux volumes des quatre de $L a$ cité antichrétienne au $X I X^{\bullet}$ siècle ne pouvait donc pas être à l'aise dans une république nettement aux mains de la maçonnerie, comme celle de $1871^{7}$. Mais l'écart grandissant entre lui et le régime de son pays natal est devenu un gouffre béant du jour où, jeune homme aux lectures voraces, il a pris note de tout un monde différent qui avait existé bien des siècles auparavant, dans les temps apostoliques, mais surtout dans le moyen âge où l'Église s'était trouvée maîtresse de l'Occident; et du jour où la Troisième République. ostensiblement fondée sur la réaffirmation de l'égalité des hommes, s'est crue obligée dans le but justement de défendre cette égalité, de légiférer les entraves dans la voie de son clergé conservateur, réfractaire aux transformations, et incapable d'abdiquer ses privilèges sociaux et politiques, le contrôle des institutions d'enseignement par exemple. On avait à la fin le phénomène d'un religieux aspirant de plus en plus à un retour en arrière soumis à un gouvernement déterminé à empêcher coûte que coûte tout recul vers le passé. Il n'y avait guère de possibilité d'entente, ni même de neutralité, entre le dom Benoît ultramontain et clérical, et la Troisième République neutre, puis laïcisante, puis carrément anticléricale.

Or il y avait trois issues à envisager: il pouvait d'abord faire son deuil de la monarchie française, accepter le régime tel qu'il était, et être de son temps; ou bien encore vivre en marge de la société française, se condamner à une stérile impuissance comme Henri Dieudonné de Bourbon, le prétendant, qui croupissait dans son château de Frohsdorf, loin de la France; enfin, aider à reconstituer cette France royale à laquelle il aspirait. Il en imagina une quatrième.

Il faut noter ici que dom Benoît n'avait rien d'un indécis. Une fois sa détermination bien prise, il avait grand mal à concéder quoi que ce fût. A un ministre protestant qui le conviait un jour à passer dans son camp, il répondait en ces termes univoques:

[...] Vous faites des voux pour que je quitte l'Eglise catholique et que je me joigne à votre troupeau; j'aimerais mille fois mieux être coupé mille fois en mille petits morceaux que de quitter le grand soleil

7 J.A. FAICHER et A. Ricker, Histoire de la tranc-maçonnerie en France, p. $326-327 ; 362-363$. 
de l'Eglise catholique pour la petite lampe fumeuse de l'hérésie protestante 8. [...]

On le devine, la cœxistence fructueuse n'était même pas possible, a priori, entre le régime républicain et le religieux royaliste.

On ne sait pas à quel moment précis ni à la faveur de quelles circonstances ce Franc-Comtois déterminé en a, pour la première fois, tiré les conséquences et, à défaut d'essayer de transformer son propre pays ou de croupir dans de stériles regrets, entrevu la possibilité de s'expatrier et songé à rejoindre le petit rameau détaché du tronc de la nationalité française, abandonné et oublié, au siècle précédent, sur les bords du Saint-Laurent et dans la terre d'Évangéline.

Dès 1881, en tout cas, les Chanoines réguliers, songeant à la situation incertaine du clergé de France. s'étaient ménagé " un asile provisoire " en Suisse, à quatre heures de distance seulement du berceau de la congrégation, à Saint-Claude ${ }^{9}$. On envisageait les fondations étrangères, également, comme une façon à la fois efficace et élégante d'éviter le service militaire, considéré comme une pure perte de temps et un tombeau des vocations religieuses. Dès 1887 au moins, dom Benoît était en contact avec Auguste Bodard, le secrétaire de la Société d'Immigration Française ${ }^{10}$, qui avait des ramifications en Europe comme en Amérique du nord ${ }^{11}$.

On a pu croire qu'à la faveur de la lecture d'un ouvrage de Gréa laissé à $M^{\mathrm{pr}}$ Taché par $\mathrm{M}^{\mathrm{kr}}$ Laflèche, l'archevêque de Saint-Boniface en était venu à faire appel aux Chanoines réguliers pour lui envoyer des renforts. La réalité est un peu différente. c'est dom Benoît qui, par personne interposée, a discrètement mais délibérément préparé le terrain pour l'implantation de cette congrégation au Nouveau Monde.

C'était en 1889, au moment où la France officielle commémorait le centenaire de la Révolution française. Les passions nationales déchaînées dans la prairie lors du soulèvement des Métis s'étaient résorbées quelque peu. Mais un nouveau souffle de fanatisme se levait: dans le pays amené à la lumière par La Vérendrye, on se préparait à consacrer le triomphe de la majorité anglaise. Des législations allaient se concrétiser qui feraient des Français d'Amérique, dans toute l'étendue de Manitoba, les "demi-citoyens" dont Noël Bernier devait évoquer le

8 Paul Benoît, a Lettre à un prédicant, distributeur de bibles protestantes (1) dans La Semaine Religieuse de Québec, 15, 39 (16 mai 1903), p. 610-613.

9 Le marquis [Anatole] DE SÉGUR, ${ }^{g r}$ de Ségur, II, p. 347-348: lettre d'Adrien Gréa à $\mathrm{M}^{\mathrm{gr}}$ de Ségur, le 13 septembre 1881 .

10 Sur la carrière de cet individu auquel l'Ouest français doit une dette du cœur: Donatien Frémont, Les Français dans l'Ouest canadien, p. 112.

11 MSACR(A), Documents historiques, Correspondance, novembre 1890 . décembre 1890, Document 28: lettre d'Auguste Bodard à Alexandre Taché, le 29 novembre 1890 . 
sort dans Fannystelle ${ }^{12}$. En peu de mois, la loi du pays décréterait, en reconnaissant un état de fait, que le Manitoba ne serait plus terre française. La minorité n'y aurait plus droit de cité. La volonté de conservation française allait être brisée par la volonté de domination anglaise et largement américaine. Dom Benoît serait marqué pour toujours par cette lutte, la plus naturelle qui puisse être, partout où deux peuples rivaux se trouvent en concurrence pour un même sol.

C'est en 1889 que, pour la première fois, des contacts s'établissaient entre les Chanoines réguliers et l'archevêque de Saint-Boniface; ils se feraient par l'intermédiaire de Auguste Bodard encore, l'un de ces Français du XIX ${ }^{\bullet}$ siècle tout dévoués à l'idée française en terre d'Amérique. Benoît lui avait laissé entendre que la petite congrégation de Saint-Claude en Jura se sentait disposée à établir des ramifications au Nouveau Monde. Il n'est pas interdit de croire que le Chanoine régulier avait également préparé le terrain auprès de son supérieur. Ainsi, sans que le religieux volontaire eût besoin de poser un geste officiel, l'archevêque de Saint-Boniface avait appris qu'il pouvait entretenir des espérances de ce côté-là. Cinq jours après que Bodard eut écrit à Taché, celui-ci écrivait à Gréa! Sa lettre, qui sollicitait des religieux pour son archidiocèse, arrivait à point sur un sol favorable. Gréa répondait qu'il enverrait un commissaire-enquêteur. Il était d'autant plus ouvert à toute cette aventure qu'il croyait. selon son habitude, voir la main de Dieu dans l'invitation que lui faisait le prélat étranger.

Ce délégué, ce ne doit pas surprendre, c'était son bras droit. dom Benoît, le grand prédisposé à aimer l'Amérique française, fille de la France restée aux yeux de certains plus fidèle à son idéal que l'original lui-même. Entre la France et le Canada, il y avait, il faut bien insister là-dessus, l'Atlantique, la Révolution française, un siècle d'oubli de la part de la mère patrie. Il était permis de croire que précisément les aspects de l'Ancien régime qui subsistaient donc au Nouveau Monde et que maints voyageurs français avaient du mal à supporter, ne lui déplairaient pas. Traverser l'Atlantique, cela équivalait à faire un retour dans le passé, pour se retrouver comme dans la France du XVIII $^{\bullet}$ siècle. Benoît avait toutes chances de s'y plaire.

Le voyage exploratoire du Chanoine régulier eut lieu de juillet à septembre 1890. Aidé financièrement par la Société d'Immigration Française, il débarqua à Québec également muni de lettres de Français aux contacts nombreux avec le petit peuple d'outre-mer, Claudio Jannet par exemple, qui lui avait fait de nombreuses mises en garde en plus de lui fournir des introductions.

12 Noël Bernier, Fannystelle, p. 173-174. 
En soixante-quatre jours, il renseigna son supérieur par lettre quarante-trois fois. Ces archives constituent aujourd'hui une mine précieuse, car, loin de rapporter le temps qu'il faisait au Nouveau Monde, le voyageur consignait au papier ses très nombreuses impressions, donnait des chiffres précis sur un tas de choses, observait, notait, comparait, dressait des résumés. Il lui arrivait même de décliner une invitation parce que, à la précédente, il s'était trouvé pour un repas " entre deux prêtres qui ne savaient rien de précis sur leur pays ".

Son voyage le conduisait au Petit-Cap; à Beaupré; au Saguenay-Lac Saint-Jean; à Montréal; en Estrie; aux Trois-Rivières; dans les Laurentides; à Ottawa; à Saint-Boniface; à Saint-Norbert; et à Saint-Léon. Il rencontrait des députés, des ministres, huit évêques, des juges, des sénateurs, beaucoup de membres du clergé, mais aussi, et surtout, nombre de familles de culuns, dunt il demandait spécifiquement à faire la connaissance et auprès desquelles il se renseignait avidement et longuement, la plume à la main.

En principe, comme le notera plus tard le brillant André Siegfried, - avec Georges Vattier, un des écrivains français de passage qui a peut-être le mieux compris les Français d'Amérique, - les ecclésiastiques venus de France étaient encouragés par les évêques à aller "coloniser la prairie ${ }^{13}$ \%. Des évêques québecois, $\mathrm{M}^{\mathrm{gr}}$ Bégin par exemple, se cantonnant dans le silence, lors du passage de Benoît, au lieu de lui faire des ouvertures pour obtenir des Chanoines réguliers, alors que ceux de l'Ouest les réclamaient à cor et à cri, le délégué de Gréa en avait vite tiré les conséquences. Aussi, il était tout naturellement arrivé en Manitoba, et dans la montagne de Pembina, dans les meilleures dispositions possibles.

De longues conversations avec $M$. Théobald Bitsche, le curé pionnier de Saint-Léon, affermirent ces dispositions. Il se borna à se renseigner abondamment auprès de lui, au lieu de visiter la région de Notre-Dame-de-Lourdes, le crut sur parole. A la demande de dom Benoît, M. Bitsche choisirait l'endroit propice, que celui-ci fixerait au carrefour des quatre cantons 6 et 7 des rangs VIII et IX Ouest. Il était entendu aussi qu'il tâcherait de faire transporter sur ces lieux, par les quelque huit familles déjà campées dans ces solitudes, du bois pour les constructions ecclésiastiques et religieuses de la future paroisse. Le curé de Saint-Léon se chargerait aussi de faire faire les inscriptions de concessions gratuites de terres des colons, recrutés en Europe, dont les demandes lui seraient référées par Benoît.

Ce qui l'attirait à la montagne de Pembina ? Il l'a écrit lui-même:

Je ne crois pas, mon très révérend Père, qu'on puisse trouver un ensemble de circonstances aussi favorables pour une fondation au

13 André Siegrried, Le Canada; Les deux races, p. 19. 
Canada: une paroisse dédiée à notre patronne, assez rapprochée des chemins de fer pour rendre faciles les communications, assez éloignée pour écarter les importuns, dans le diocèse d'un évêque religieux, le plus grand év. peut-être du Canada, auprès d'un curé exceptionnellement ami, dévoué, habile, sur une terre très fertile, ayant bois et eau, et où n. pouvons obtenir pour chacun des pères qui viendront un lot, c-à-d. 64 hectares et 1/2 dans une paroisse nouvelle où n. pourrons recevoir nos colons.

En voyant tout cela, $[s i c]$ mon très révérend Père, j'ai cru qu'une vision me passait devant les yeux ${ }^{14}$.

Il y avait quelques autres raisons. Contournée par les vagues successives de la colonisation, à l'exception de la région de Swan Lake peuplée tôt, la montagne de Pembina aux terres montagneuses souvent de troisième ordre constituait une grande tache blanche sur les cartes de 1880-1890 ${ }^{15}$. Même un certain nombre de ceux qui s'y étaient établis primitivement avaient abandonné leurs foyers pour aller chercher ailleurs des terres moins pénibles à défricher et moins ingrates. Il y avait donc de belles possibilités d'expansion dans toute cette partie de Manitoba : pour le peuplement et pour l'établissement canonique primitif. En effet, choisi en fonction des possibilités de colonisation qu'il offrait aux Français de l'est, un peu parce qu'il rappelait les terres montagneuses du Jura, le territoire de la montagne de Pembina avait également, aux yeux de Benoît, le mérite d'être un lieu désert que les religieux pourraient mettre en valeur sans déposséder aucun curé séculier. Mais aussi, en raison de son peuplement épars, il permettrait à la fois une expansion de la population civile et une extension de l'œuvre canonique elle-même. En choisissant cet endroit, il s'était donc laissé guider par ses sentiments intérieurs d'une part, quant au pittoresque de ce pays coupé de ravins, par exemple, tout en obéissant d'autre part à de multiples motifs pratiques, - telle la proximité des chemins de fer, que le cadre de cette communication a à peine permis d'effleurer.

A son retour à Saint-Boniface, le Chanoine régulier demandait à T. A. Bernier, dont l'ouvrage Le Manitoba, champ d'immigration avait attiré son attention sur l'ouest, et à Joseph Dubuc, qui était lui aussi venu le saluer à son passage à l'archevêché, un enfant qu'il pourrait emmener en France avec lui, pour y être élevé dans et pour la vie

14 JRG(A), Dossier Paul Benoît, lettres émises, Benoît à Gréa, juilletseptembre 1890, Document 28: lettre de Paul Benoît à Adrien Gréa, le 13 août 1890.

15 En 1882, vingt-huit sections, en gros, de revendiquées, sur les cent quarante-quatre que comptaient les quatre cantons dont il s'agit: APC, Division des cartes: Canada, Department of Agriculture, H3, 501 - 1882, Map of a portion of the Province of Manitoba, showing Dominion lands surveyed, and distinguishing certain lands disposed of, 12 janvier 1882.

Sur la qualité inférieure des Terres: Canada, Department of the Interior, Description of the province of Manitoba, p. 199: County of Rock Lake, Range IX, 6 , Outlines.

$\mathrm{Si}$ une forte proportion de toute cette région était considérée comme impropre $\dot{a}$ la culture, il convient de noter qu'elle contient également un certain nombre de terres qui comptent parmi les plus belles, sans contredit, de Manitoba. 
religieuse. L'un et l'autre avait consenti à laisser aller " tous ceux qui voudraient embrasser » la vie canonique. Et, effectivement, il était reparti en compagnie de Augustin Bernier et de Antonin Dubuc.

Ses sentiments à son retour? Ils étaient résumés dans un mot de remerciements qu'il écrivait, le jour de son départ pour la France, le 26 août 1890, à $\mathrm{M}^{\mathrm{gr}}$ Thomas-Étienne Hamel, ancien supérieur du séminaire de Québec:

Le Canada est une terre de foi et de grandes vertus. Partout j'ai pu constater qu'il faut chercher ici la véritable France. Je crois que le bon Dieu appelle ce beau pays à de grandes destinées, si ceux qui le dirigent ont assez de lumières pour empêcher l'introduction de la Révolution ${ }^{16 .}$

Déhordant d'enthousiasme. Benoît avait présenté son rapport à Gréa, recommandant une fondation à Notre-Dame-de-Lourdes. Le supérieur avait acquiescé, sans délai. Dès le 26 septembre 1890, dom Benoît livrait à la publicité dans les départements de l'est de la France, et dans la Suisse romande, une circulaire imprimée invitant les montagnards à s'expatrier avec lui ${ }^{17}$. Il montrait bien par deux phrases lourdes de sens jusqu'à quel point il croyait avoir trouvé outre-mer ce paradis terrestre gâché dans son pays natal par la Révolution française: "Nous n'avons pas besoin d'ajouter que tout notre dévouement sera au service des colons qui nous accompagneront. C'est pour eux que nous venons de visiter le Canada; c'est pour eux que nous quittons notre patrie, pour toujours, nous le croyons du moins ${ }^{18}$."

Huit jours après que la circulaire eût "été insérée pour la première fois dans les journaux ", il avait déjà " reçu douze demandes de douze familles désirant partir au printemps ${ }^{19}$ ». En dépit de pressions gouvernementales, il devait persister dans son œuvre de recrutement ${ }^{20}$. Le 29 mars 1891, il avait recruté « 66 familles ", mais comme plusieurs ne pouvaient pas liquider "toutes leurs affaires" en

16 QQS(A), Dossier Paul Benoît, Université 44, $\mathrm{n}^{\circ}$ 44: lettre de Paul Benoît à Thomas-Etienne Hamel, le 26 août 1890.

17 QTS(A), Dossier Paul Benoît, A2-15-03: Paul Benoît, Emigration au Canada, circulaire imprimée, le 26 septembre 1890; également MSACR(A), Documents historiques, Correspondance, juillet 1890-août 1890, Document 40.

18 Ibid.

19 MSACR(A), Documents historiques, Correspondance, juillet 1890-août 1890, Document 10: lettre de Paul Benoît à Alexandre Taché, le 14 octobre 1890. Les demandes continuaient car le lendemain il en avait quatorze: $\operatorname{OOACR}(\mathrm{A})$, Dossier Chanoines réguliers de l'Immaculée Conception, Missions, 1890-1908, Document 2: lettre de Paul Benoît à Thomas Duhamel, le 15 octobre 1890.

20 MSACR(A), Documents historiques, Correspondance, juillet 1890-août 1890, Document 11: lettre de Paul Benoît à Alexandre Taché, le 25 novenbre 1890. * Le Préfet [du Jura] m'a dénoncé au Ministre de l'Intérieur qui, par le Préfet de l'Isère, le Sous-Préfet de S. Marcellin et le Maire de S. Antoine, m'a signifié de me désister de mon œuvre. " 
temps, il annonçait son intention de partir avec « 30 familles environ * seulement ${ }^{21}$.

Les "grands fruits " qu'il espérait de son ministère au Nouveau Monde découlaient des projets capiteux pour lesquels il se passionnait dans ce temps-là ! En effet, dès sa seconde lettre écrite à Taché après son retour en France, il avait énoncé une suite de conclusions auxquelles il était arrivé. A son sens, l'équilibre des nationalités venait d'être rompu au Manitoba. C'était manifeste à partir de la révocation des droits de la minorité, l'Assemblée législative de Manitoba ayant les 19 et 22 mars de la même année supprimé le système d'écoles confessionnelles, l'usage officiel de la langue française, et les fêtes légales d'origine catholique. Le renversement des proportions ethniques de l'immigration vers cette province pouvait seul rétablir cet équilibre, redonner l'ascendant puis la prédominance à l'élément catholique et français. Ce serait comme une conversion de Manitoba à la cause catholique. Suivraient, à plus ou moins brève échéance, celle du Canada par la prédominance de Québec et de Manitoba, les deux provinces catholiques et françaises, puis viendrait celle de l'Amérique protestante par l'intermédiaire de ce Canada à prédominance catholique et française. Enfin découlait la première étape de la conversion de l'Orient. - toujours « la Chine et le Japon ", - par l'intermédiaire de cette Amérique convertie ${ }^{22}$ ! C'est bien dans cette optique que Paul Benoît s'est expatrié pour toujours. L'œuvre était de taille !

S'il y avait là le rêve d'un idéologue, il avait quelque fondement dans la réalité, ou du moins semblait en avoir. Dom Benoît, dans les premières années en tout cas, était déterminé « à former chaque année un village nouveau dans le Canada ${ }^{2: 3}$ ". A ce propos, il en sera bien désabusé dans les quelques années suivant son passage au Nouveau Monde, en s'apercevant que l'issue de la question des écoles de Manitoba était une solution permanente, consacrant la défaite française dans l'Ouest canadien. La majorité manitobaine, une fois qu'elle se fut dotée de structures et d'une population qui reléguaient le français à l'état de langue morte, eut vite fait de tourner la page sur cette question, pour se consacrer au développement économique. Quelles que pussent être les idées des Franco-Manitobains là-dessus, ou celles de leurs compatriotes à l'extérieur, les Anglo-Manitobains, eux, avaient décidé, une fois pour toutes, que leur province était arglaise ${ }^{24}$. Au soir de sa vie, l'archevêque de Saint-Boniface s'en rendait compte;

$\because 1 \quad$ MSACR(A), Documents historiques, Correspondance, mars 1891-avril 1891, Document 8: lettre de Paul Benoît à Alexandre Taché, le 29 mars 1891.

22 MSACR(A), Documents historiques, Correspondance, juillet 1890-août 1890, Document 7: lettre de Paul Benoît à Alexandre Taché, le 17 septembre 1890.

23 Félix Vernet, Dom Gréa, 1828-1917, p. 114: lettre de Paul Benoît à Henri Benoît, le 6 janvier 1890.

24 W. L. Morton, Manitoba. A history, p. 250. 
vers le même temps, Auguste Bodard même en venait à combattre toute émigration vers le Manitoba comme une perte, car il réalisait que cette province avait définitivement échappé à l'idée française.

Pour l'instant, Benoît emmenait au Nouveau Monde « 3 pères, avec 40 colons ", français et suisses. Arrivés à Saint-Boniface le 7 mai 1891, ils commençaient leur tentative, au milieu de la forêt, une semaine plus tard. Le choix exercé par M. Bitsche fut confirmé par les vœux de la nouvelle population, et très tôt on se mit à l'œuvre, car il s'agissait de préparer l'établissement religieux avant les premières neiges. Dès le 26 mai 1891, - douze jours après l'arrivée sur les lieux, - le Chanoine régulier montrait qu'on ne perdait pas de temps: "Nous commençons cette semaine une petite école primaire pour nos petits enfants, si ignorants ${ }^{25}$.

Puis, de Notre-D̄ame-de-Lourdes, vint une lettre montrant, mieux que toute autre combien, en quelques douze semaines, les desseins de Benoît s'étaient changés en réalités, et ses projets d'expansion rapprochés rapidement: les Chanoines réguliers s'occupaient des offices religieux à Saint-Léon aussi bien qu'à Notre-Dame-de-Lourdes, en raison de la maladie et de l'absence de $\mathrm{M}$. Bitsche; la petite communauté de quatre habiterait le monastère "dans une huitaine de jours "; les dépenses, pour l'église et le monastère s'élevaient " autour de $\$ 3,000$ ", comparées aux $\$ 4,000$ prévus; les conditions de la main-d'œuvre, venue d'Europe, étaient " exceptionnellement heureuses "; les Chanoines réguliers prendraient dès l'automne, conformément aux vœux de Gréa, des "enfants oblats * se destinant à la vie religieuse; il comptait, pour l'hiver, loger aussi " une trentaine d'enfants " dans " un pensionnat primaire " aménagé à même le monastère; les Chanoines réguliers faisaient déjà l'école " tous les jours »; quelques confrères religieux arriveraient le 15 octobre pour lui prêter main-forte, entre autre deux fuyant devant les lois militaires françaises, avec aussi "quelques colons"; un troisième convoi de colons, "probablement important ", était annoncé pour le printemps, et, malgré les désirs de l'évêque de Saint-Albert appelant des secours vers lui, Benoît disait incliner « à la fondation d'une nouvelle paroisse dans le Manitoba; l'archevêque d'Ottawa insistait auprès de Gréa pour que les Chanoines réguliers recueillent a la succession des Jésuites au lac Nominingue », au nord de Montréal, bien qu'il ne pouvait être question, affirmait Benoît, de diriger là les colons d'Europe, ce qui aurait été, dans son esprit, " contraire au bien général de l'Église ${ }^{26}$ ".

25 MSACR(A), Documents historiques, Correspondance, mai 1891-juin 1891, Document 8: lettre de Paul Benoît à Alexandre Taché, le 26 mai 1891.

26 MSACR (A), Documents historiques, Correspondance, décembre 1891décembre 1891 (2), Document 24: lettre de Paul Benoît à Alexandre Taché, le 11 [incertain, rature] août 1891. Pour l'instant, voulait-il dire, il valait mieux ne pas disperser ses effectifs sur le Nord-Ouest, trop vaste à conquérir, ni sur le Québec, acquis à la religion catholique. 
Enfin, les offices se faisaient à l'église depuis le 21 août 1891; le monastère était occupé depuis le 24 août. Cinq jours plus tard, tout était rasé par les flammes. "Les pertes, annonçait le Manitoba, sont de $\$ 5,000$; pas d'assurances ${ }^{27}$. 》

Certaines pertes paraissaient bien irréparables. Le Chanoine régulier confiait à l'évêque des Trois-Rivières: "J'avais réuni de 30 à 50 mille textes pour un grand ouvrage sur la vie et l'éducation des clercs dans les siècles passés; je comptais faire là une ouvre nouvelle. car le sujet n'a point encore été traité: le manuscrit, comprenant la matière de 7 ou 8 volumes, est resté dans les flammes ${ }^{28}$." Le mois suivant, encore au même, il précisait qu'il avait eu "plusieurs ouvrages en préparation ", dont celui qu'il avait déjà mentionné n'était qu'un.

Il ne pouvait pas être question de renoncer au projet de colonisation. Benoît montrait sans équivoque qu'il n'y songeait pas: le jour même de l'incendie, les nombreux offices religieux prescrits par les règles canoniques avaient eu lieu comme si de rien n'était. A l'évêque des Trois-Rivières, il écrivait: "Nous ne nous décourageons pas, nous allons recommencer; mais nous avons besoin des secours de la charité. » Ceux-ci viendraient de $\mathrm{M}^{\mathrm{gr}}$ Laflèche, des évêques; il y aurait des appels au secours, dans la Vérité; à Fribourg, en Suisse; dans la Semaine Religieuse de Québec; en France, par l'intermédiaire de Gréa: à SaintBoniface et ailleurs. Dès le 8 janvier 1892, Benoît estimait avoir recueilli, en argent ou en promesses de secours, environ $\$ 3.400$, mais il lui restait $\$ 672$ à payer pour ses " cendres".

Le $1^{\text {er }}$ octobre 1891, environ un mois après l'incendie, une nouvelle construction était en marche, à base de billots recueillis localement, et équarris à la hache, et non plus faite de planches comme les premières. Un seul édifice servirait à la fois d'église et de monastère. Le 15 octobre, le "carré " en était levé, quelques jours plus tard la construction en était avancée. Vers le 2 décembre 1891, trois mois après l'incendie, les religieux s'y installaient. On était de nouveau en marche, après des semaines pénibles.

Dom Benoît, toujours porté aux déterminations nettes et franches, avait tiré une conséquence de l'incendie:

Je désire contribuer à la fondation de quelques paroisses dans le Manitoba et le Nord-Ouest: c'est là une grande œuvre à laquelle je désire dévouer le reste de ma vie. Le bon Dieu a semblé m'y appeler par des signes nombreux. L'un des derniers est la destruction de mes manuscrits dans cet incendie qui nous a frappés. [...] Il me semble que le bon Dieu m'appelle à bâtir des églises et à prêcher plutôt qu'à composer des livres 29 .

27 "Incendie », dans Le Manitoba, XX, 47 (2 septembre 1891), 2.

28 QTS(A), Dossier Paul Benoît, A2-15-04: lettre de Paul Benoît à LouisFrançois Laflèche, le 5 septembre 1891.

29 QTS(A), Dossier Paul Benoît, A2-15-06: lettre de Paul Benoît à LouisFrançois Laflèche, le 2 octobre 1891. 
Ce qui ne l'empêchait pas de corriger les épreuves de son Histoire de l'abbaye et de la terre de Saint-Claude, en deux gros volumes, dont le second paraîtrait en 1892.

Sa situation financièrc fut souvent précaire, mais il devait parvenir, dès 1892 , à force de démarches, à remplacer le monastère en s'imposant " comme règle absolue de ne pas [se] mettre dans les dettes". Au fait, celui-là, avec partie centrale et quatre ailes, devait surgir de bonne heure au printemps. Les Chanoines réguliers rouvraient \& une petite école primaire ", y faisant "la classe trois jours par semaine " à " une douzaine d'enfants ». Ils acceptaient déjà, de Saint-Boniface, des enfants oblats se destinant à la vie religieuse. Fidèle à sa détermination d'y aller selon ses moyens, il interrompait la construction, en 1892, qui se continuait l'été suivant, pour être finalement bénie le 27 août 1894 . Une nouvelle église aussi surgirait en 1898 , et, à son archcvêquc qui s'inquiéterait de la disposition de cette bâtisse, Benoît pourrait signaler avec sérénité qu'il avait bel et bien fait faire "une grande crypte, plus grande que celle de la cathédrale de S. Boniface».

Entre temps, dom Benoît transigeait avec les Chanoinesses régulières des Cinq-Plaies de Lyon, qu'il espérait voir remplir le rôle d'institutrices; avec les Chartreux, pour lesquels il voyait un désert convenable dans les ravins pittoresques de l'extrémité sud-ouest de sa paroisse; avec les Maristes, qu'il destinait à l'enseignement. Si tout s'était passé selon ses vœux, la paroisse aurait été dotée généreusement de quatre communautés religieuses!

Saint-Léon, au décès de M. Bitsche, le 18 mars 1892, était attribuée aux Chanoines réguliers, puis abandonnée à l'archevêque deux ans plus tard, par manque provisoire de sujets.

Mais ce n'était qu'une partie remise. Les possibilités d'expansion étaient excellentes. Plus tard, le religieux devait avouer que $\mathrm{M}^{\mathrm{gr}}$ Taché leur avait offert nombre de paroisses qu'ils n'avaient pu accepter, faute de personnel.

Avec l'enthousiasme, bien sûr, les projets reprenaient. nombreux. En 1892, on perçait une route importante devant traverser la paroisse et la joindre aux centres voisins; les colons y gagnaient des salaires extrêmement utiles pour eux dans leur condition de pauvreté. L'intervention du curé actif n'était pas étrangère à ce progrès. On obtenait aussi des subventions municipales pour l'école locale. Déjà l'agent général des Travaux publics et le préfet de la municipalité de Lorne, en même temps député provincial, qui accordaient ces dépenses, s'arrachaient les faveurs de Benoît. Mais lui ne s'y trompait pas: "Je pense que le but électoral n'est pas étranger à [ces] démonstrations de bienveillance ${ }^{30}$. " Le chef religieux de Notre-Dame-de-Lourdes serait long-

30 MSACR(A), Documents historiques, Correspondance, février 1892-mars 1892, Document 48: lettre de Paul Benoît à Alexandre Taché, le 10 mars 1892. 
temps considéré comme un facteur politique important dans la montagne de Pembina, dont on avait intérêt à se ménager les bonnes grâces, tellement il avait de prestige auprès des populations venues s'y établir sous son égide. On verrait même un homme politique manitobain solliciter son appui pour sa candidature au parlement fédéral, mais se voir refuser par le religieux aux idées précises.

Dès 1892, l'année où paraissait le second volume de son Histoire de labbaye et de la terre de Saint-Claude, il entreprenait les démarches dans les quatre cantons orientaux des huit cantons primitifs qui constituaient la paroisse de Notre-Dame-de-Lourdes, pour faire doter ce territoire du nom de Saint-Claude, contre d'autres qui voulaient le baptiser du nom de Maisonneuve. Les Chanoines réguliers y suivraient de près, à titre de desservants, les premiers colons français qui se lançaient à la conquête de ces marais infestés qui feraient place en peu d'années à une seconde paroisse prospère.

Le supérieur des Chanoines réguliers au Nouveau Monde prêchait d'exemple, à en croire un texte de A.-G. Morice:

Un petit détail donnera une idée de son amour pour la prière et de sa passion pour le travail. Après s'être levé, la nuit précédente, pour psalmodier matines et laudes avec ses frères en religion, après avoir récité les autres heures en commun et passé son temps libre à bûcher dans la forêt, il trouvait encore le moyen de réciter chaque jour en particulier le psautier tout entier, c'est-à-dire pas moins de 150 psaumes, dont quelques-uns sont très longs 31 !

Faut-il voir dans ce centre de Notre-Dame-de-Lourdes une colonie en tout et partout insolite, de type monastique et d'aspect médiéval ? Non, excepté que la colonie fut créée de toutes pièces, sous l'égide du supérieur religieux, avec une population neuve, homogène par la langue et la foi, diverses par les origines et par les convictions. - différences qui iraient se résorbant d'ailleurs, - elle n'était pas, comme telle, très différente des autres.

Néanmoins, la présence canonique a pesé bien plus lourdement sur la colonie que ne l'eût fait la direction ecclésiastique d'un a prêtre noir». Les Chanoines réguliers imprimant aux longs offices religieux un caractère surchargé; ayant pris en charge le bureau de poste; s'étant fait instituteurs publics; ayant constitué une école de latinité, cléricale, pour les enfants oblats; agissant comme directeurs de consciences; s'étant établi une exploitation agricole, comme défricheurs puis comme cultivateurs, dans les terres situées au centre de la paroisse; se chargeant de l'état civil et des recensements ecclésiastiques; appliquant sans relâche la théorie de la dîme face à des populations européennes éberluées de découvrir un septième commandement de l'église dans p. 125 .

31 A.-G. Morice, Histoire de l'Eglise catholique dans l'Ouest canadien, IV, 
l'archidiocèse de Saint-Boniface, et d'autant plus que leurs voisins anglais n'étaient pas astreints à la dîme; rapportant les progrès de la colonie dans les journaux; intervenant dans les élections municipales, provinciales et fédérales, il était tout normal que, très tôt, les esprits français les plus avancés eussent du mal à s'accommoder de ce cléricalisme, et qu'ils quittassent Notre-Dame-de-Lourdes pour d'autres parages. Sans doute Saint-Claude s'est-elle un peu peuplée grâce à ces circonstances précises ${ }^{32}$.

La présence québecoise à Notre-Dame-de-Lourdes, par contre, a eu tendance à augmenter dans les premières années, - ses pourcentages approximatifs de 30,5 pour 1893 ; de 26,0 pour 1895 ; de 33,5 pour 1897; de 26,9 pour 1899; de 28,9 pour 1900 ; et de 28,9 pour 1904, l'indiquent, - jusqu'à ce que l'afflux de nouveaux colons européens, conjugué avec une hausse de la natalité dans le groupe de France réduise la proportion qu'elle occupait ${ }^{33}$. Fatalement, le départ de

32 En 1899, sur 137 familles à Notre-Dame-de-Lourdes, quarante-trois seulement avaient accepté de payer la dìme. Cette question était la pierre d'achoppement des curés de la montagne de Pembina: MSACR(A), Documents historiques, Correspondance, varia 1899-janvier 1900, Document 9: [Paul Benoît], Population catholique de Notre-Dame-de-Lourdes et de ses missions, sans date.

33 Il est intéressant de noter que le comportement des Français venus dans la montagne de Pembina s'est vite modifié au contact des descendants de l'ancienne Nouvelle-France. La natalité comparée à Notre-Dame-de-Lourdes constitue un cas d'espèce. Dans les trois premières années, de 1891 à 1893, il y avait eu vingt-six naissances québecoises contre quinze françaises seulement, sur un total de quarantesix, ce qui voulait dire que les familles d'origine québecoise, comprenant le tiers de la population, fournissaient près des deux tiers des naissances. Mais la natalité française aurait augmenté: de 1891 à 1895 , il y avait eu quarante naissances québecoises contre trente-cinq françaises, sur un total de quatre-vingt-sept, alors que les familles québecoises comptant pour les deux septièmes de la population à peu près, et les françaises pour les quatre septièmes à peu près, les premières fournissaient néanmoins près de la moitié des naissances, et, dans les chiffres, plus que les secondes elles-mêmes. Mais, phénomène intéressant, de 1891 à 1897, malgré l'accroissement proportionnel des familles d'origine québecoise qui formaient de nouveau le tiers de la population, il y avait eu soixante-cinq naissances françaises contre cinquante-neuf québecoises, sur un total de cent quarante-cinq, les Français comptant pour la moitié de la population à peu près, et parvenant presque à fournir la moitié des naissances, enfin.

Les chiffres sont extraits de trois rapports de Benoit, parus dans Le Manitoba, en 1894, en 1896 et en 1898. Au reste Benoît était très conscient des disparités de natalité dans les nationalités représentées à Notre-Dame-de-Lourdes. C'est sur ces chiffres qu'il étayait des projections démographiques des Français d'Amérique pour la fin du $\mathrm{XX}^{\mathrm{e}}$ siècle. Cf. ses observations intéressantes: Paul BENoît, - La paroisse canadienne-française », dans Revue catholique des institutions et du droit, 37 (2e semestre 1906), 215-252. Enthousiaste, il s'écriait: - [...]; la paroisse canadienne-française, cellule mère et matrice où se forme une race d'un immense avenir; la paroisse canadienne-française, terre de Gessem, où le peuple de Dieu se multiplie pour conserver à lui-même et donner à toute l'Amérique du Nord le salut, c'est-à-dire la vie catholique et la civilisation supérieure dont cette vie est la source.,

Mais Benoît n'avait nullement oublié de fonder ses conclusions sur des chiffres précis. Cf. la p. 250; pour Notre-Dame-de-Lourdes: c L'excédent de 294 naissances est précisément ce qu'il doit être pour l'augmentation du double de la population en vingt ans., 
Français radicaux au loin, la venue de quelques familles plus religieuses, renforçait le caractère clérical primitif de cette colonie. En même temps, par la nature même de la mentalité immigrante, ayant tendance à croire, en venant au Nouveau Monde, qu'elle devait faire table rase de son passé et de ses habitudes (sociales seulement), les colons européens, quoique retenant leurs particularismes culturels. le goût de la lecture, par exemple, se plièrent vite aux usages politiques. sociaux et agricoles québecois et manitobains, sauf la dîme!

La colonie étant tenue sous la poigne ferme du supérieur. il régnait une paix remarquable à Notre-Dame-de-Lourdes. Le curé ne reculait pas devant les grands moyens pour imposer les droits de l'Église. Aussi, somme toute, la victoire venait à Benoît, lentement et sûrement. La réception des sacrements en 1904, par « 5 ou 6 français. [sic] qui sien étaient tenus éloignés depuis leur arrivée et ne s'étaient probablement pas confessés depuis 20 ou 30 ans, peut-être plus encore " lui causait un plaisir indicible, car il touchait au but, la paroisse intégralement pratiquante: "Par suite de ces retours si consolants, il ne reste plus qu'une seule place de notre paroisse où un groupe de français [sic] encore ne se confessent pas et ne communient pas. Que votre bénédiction et vos prières, Monseigneur, daignent leur obtenir. à eux aussi, la grâce de la conversion ${ }^{34}$ !"

Aussi. Benoît. une quinzaine d'années après qu'il se fut établi au Nouveau Monde, était-il un homme très heureux: "Votre Grandeur me pardonnera la longueur de ces détails mais c'est pour lui dire que nous bénissons Dieu d'avoir incliné notre vénérable fondateur à se rendre aux instances de votre prédécesseur, de glorieuse mémoire. et de nous avoir envoyés sous sa houlette et sous la vôtre ${ }^{35}$. "

Il y avait en théorie, au temps de dom Benoît. quinze paroisses en formation dans la montagne de Pembina, - cette réalité ethnique, et non morphologique, ce pays français allant de Haywood à l'est jusqu'à Saint-Alphonse à l'ouest, - : cinq dans la plaine, trois anglaises, trois dans l'est de la montagne, et quatre dans l'ouest. A la faveur de circonstances de toutes sortes, c'était sur celles-là que les Chanoines réguliers pouvaient espérer s'étendre.

Un facteur important dans la vie de Notre-Dame-de-Lourdes et de Saint-Claude. c'était l'arrivée de nouveaux colons. Dom Benoît

JRG(A), Dossier Paul Benoît, lettres émises, Benoît à Gréa, Document 20: lettre de Paul Benoît à Adrien Gréa, le $1^{\text {er }}$ août 1890 ; n'avait-il pas écrit: " Résumé de mes impressions sur le Canada. $1^{\circ}$ Ce qui excite le plus mon estime pour le Canada c'est le grand nombre des enfants. Je crois que nulle part les familles ne sont aussi nombreuses, dans le monde entier"?

$34 \operatorname{MSACR}(\mathrm{A})$. Correspondance, Somerset, Document 176: lettre de Paul Benoît à Adélard Langevin, le 6 juillet 1904.

$35 \operatorname{MSACR}(\mathrm{A})$, Correspondance, Somerset, Document 175: lettre de Paul Benoît à Adélard Langevin, le 18 juin 1904. 
avait été suivi en octobre 1891, l'année de son arrivée, par un second convoi venu sous l'égide de Marie-Antoine Straub. Un troisième convoi, " en avril 1892 ", de dix colons; un quatrième, " au printemps de 1893 », de soixante et onze colons; et un cinquième, "en 1894», de quinze colons, remplissaient vite ces paroisses ${ }^{36}$, du fait aussi que ces colons, venus souvent sans leurs familles lorsqu'ils s'étaient établis, les avaient par la suite fait venir. Très peu d'années après sa fondation, l'établissement commençait déjà l'essaimage vers l'Ouest, anticipé par Benoît. Dans un tableau, celui-ci estimait à $\$ 8,350$ le « total des dépenses " de sa communauté pour l'ensemble de cette ouvre, de 1890 à 1895 environ ${ }^{37}$. Mais ils avaient jeté les bases d'une prospérité et d'une expansion rapides, qu'il notait avec satisfaction dans un premier rapport statistique de $1893^{38}$.

$\mathrm{Si}$, à la fin, Saint-Claude a été une fondation plus importante que Notre-Dame-de-Lourdes, la réussite essentielle pour dom Benoît, il fallait que ce fût sa colonie primitive. Là étaient les institutions de la maison majeure qu'il était chargé de fonder; et c'était de là, la fondation étant assise sur des bases solides, que devait partir le mouvement d'expansion.

Il a laissé pour Notre-Dame-de-Lourdes des rapports statistiques éminemment précis que pourraient lui envier d'autres paroisses, parce que "veau, vache, cochon, couvée ", tout y était énuméré avec une rigoureuse exactitude. Ils permettent de suivre la marche en avant de la localité où se fit sa première fondation. Surtout, ils permettent de saisir, pour cette paroisse qui n'avait $a$ priori aucun élément de permanence, les deux éléments qu'il devait lui offrir: d'abord le peuplement massif de ce territoire, suffisant pour lui donner de l'élan; ensuite, un tronçon de chemin de fer pour lequel il a multiplié les démarches et, grâce à son influence électorale, obtenu gain de cause.

S'il n'est pas possible d'indiquer ici les sources des statistiques suivantes, c'est qu'elles proviennent d'une compilation faite à partir de documents trop nombreux à énumérer. Elles ont été laissées par Benoît lui-même, dont on peut révoquer en doute certaines idées, mais non la précision des faits.

Malgré sa position géographique, - en marge des chemins de fer, - qui aurait bien probablement pu la faire péricliter en faveur des paroisses voisines ${ }^{39}$, Notre-Dame-de-Lourdes connut un développe-

36 ASJ (CF), Document 5316-1: [Paul Benoît], Euvre de la colonisation par les RR.PP. Chanoines réguliers de l'Im. Conc., sans date [vers 1895].

37 Ibid.

38 Paul Benô̂t, \& La colonisation française au Manitoba », dans Le Manitoba, XXII, 22 (8 mars 1893), 1.

39 Comme Saint-Daniel en faveur de Saint-Claude; Saint-Léon en faveur de Somerset; Bruxelles en faveur do Swan Lake; et Saint-Alphonse en faveur de Mariapolis. 
ment adéquat. Alors que «quatre ans après la fondation, le centre » de Saint-Brieux, en Saskatchewan, ne devait compter "encore que soixante foyers ${ }^{40}$ ", la première paroisse de dom Benoît, deux ans après sa fondation, en comptait quatre-vingt-quinze. Elle avait, la même année, en 1893, 482 habitants; en 1895, 567; en 1897, 628; en 1899, 714 ; en 1902, 767; et en 1904, 860. Progrès relativement rapides, mais très sûrs. C'est dans ces années-là, que Robert Rogers, le ministre des Travaux publics de Manitoba, et député de la circonscription électorale de Manitou, englobant une partie de la montagne de Pembina, cédait aux instances répétées de Benoît, qui lui avait fait valoir le danger électoral que représenterait son refus, et faisait construire un tronçon de chemin de fer, greffé à la ligne principale Carman - Somerset vraisemblablement au coût de $\$ 125,000^{41}$, assurant ainsi l'avenir de la localité... et son propre bonheur politique! Dom Benoît devait se réjouir de ce que cet élément capital de permanence aboutissait " tout près de l'église, trop près même ${ }^{42}$ ".

$\mathrm{Si}$, dom Benoît avait laissé entendre au ministre, "les promesses faites 》 étaient oubliées, si les colons de Notre-Dame-de-Lourdes n'obtenaient pas ce qu'ils désiraient, c'était leur député qui subirait les conséquences de ce refus, car, disait le Chanoine régulier, « il n'est pas en mon pouvoir d'empêcher qu'ils ne passent en masse de l'autre côté ${ }^{43}$ ». Mais Rogers était trop fin politique pour ne pas comprendre le sens véritable de la phrase.

Les choses s'étaient réglées de la façon dont Benoît l'avait souhaité. Aussi le ministre y avait-il trouvé son compte. Dès 1903, le curé qui se louait déjà parce qu'il touchait presque au but, c'est-à-dire la population intégralement catholique, pouvait aussi écrire: "Dans notre région, la presque totalité des votes sont conservateurs. Les temps ont bien changé ${ }^{44}$. »

Rogers lui en savait gré, et veillait à poser de petits gestes susceptibles de plaire à son allié dans la montagne de Pembina. Viendrait le jour où ce franc-maçon, - avec Joseph de Maistre le seul peut-être que l'auteur de La franc-maçonnerie ait jamais eu en grande estime. lui ferait offrir deux crucifix: un don religieux du franc-maçon aux croyances élastiques fait par l'intermédiaire d'un archevêque à un catholique intransigeant qui avait versé deux volumes au procès de la

40 Donatien Frémont, Les Français dans l'Ouest canadien, p. 117.

41 MSACR(A), Correspondance, Somerset, Document 168: lettre de Paul Benoît à Adélard Langevin, le 16 mars 1904.

42 MSACR(A), Religieux, Chanoines réguliers de l'Immaculée Conception, Document 63: lettre de Paul Benoît à Adélard Langevin, le 26 juin 1905.

43 MSACR(A), Correspondance, Somerset, Document 188: copie d'une lettre de Paul Benoît et al. à Robert Rogers, le 25 [incertain] mai 1905.

44 MSACR(A), Religieux, Chanoines réguliers de l'Immaculée Conception, Document 26: lettre de Paul Benoît à Adélard Langevin, le 20 juillet 1903. 
maçonnerie! En privé, Langevin se rendait compte, bien sûr, que Rogers offrait " de l'encens à la croix et au croissant » avec une égale gravité. Dom Benoît, par contre, ne semble jamais avoir perdu ses illusions du côté du ministre "roué ".

Aussi, la paroisse continuerait de progresser, sous l'égide de son fondateur et de la même manière après son départ: elle avait 946 habitants en $1906 ; 1,025$ en 1908 , et 1,247 le 16 novembre 1910 . Ces deux éléments allaient naturellement de pair, un tel prolongement ne venant que comme réponse aux aspirations et aux besoins d'une population considérable, mais le peuplement se continuait essentiellement parce qu'il s'y trouvait des éléments de progrès, notamment le chemin de fer.

Il n'est pas possible de déterminer si la publicité que dom Benoît donnait dans les journaux et les revues aux progrès de sa colonie, de 1893 à 1913, a joué un rôle important dans le recrutement de nouveaux colons européens ou québecois, ou si c'est parce que le courant était établi qu'il se perpétuait lui-même ${ }^{45}$. Quoi qu'il en soit, les immigrants affluaient, témoins plusieurs lettres du supérieur. En 1906, il pouvait même écrire: "Nous avons reçu cette nuit, à $10 \mathrm{~h} /, 7$ basques, [sic] âgés de 18 à 25 ans; ce sont les premiers colons qui nous arrivent de cette province si catholique, dont on dit que le diable n'a pas pu y pénétrer, parce qu'il n'a pu en apprendre la langue ${ }^{46}$. A la fin, NotreDame-de-Lourdes serait devenu l'agglomération rurale de langue française la plus considérable de l'archidiocèse de Saint-Boniface. Et $\mathbf{M}^{\mathrm{gr}}$ Langevin se louait des progrès accomplis sous la direction de son curé à la robe blanche. Dès 1898, dans une attestation de forme impersonnelle, c'est-àdire à qui de droit, et qui semble avoir eu pour but d'encourager le lecteur à prêter 10,000 francs ou davantage aux Chanoines réguliers de Notre-Dame-de-Lourdes pour des œuvres qui n'y sont pas précisées, l'archevêque montrait sans équivoque combien il était satisfait de la première fondation de Benoît:

Il s'agit d'une cuvre essentiellement religieuse et française. De toutes les colonies françaises établies dans Manitoba, c'est celle de N. D. de Lourdes, sous l'habile direction du Rév. P. Dom Paul Benoit, [sic] qui a mieux réussi, parce qu'elle a été fondée sur le dévouement et l'abnégation sacerdotale ${ }^{47}$.

L'archevêque se portait garant de la somme qui serait prêtée, signe qu'il approuvait l'intendance du curé colonisateur. Deux ans plus tard,

45 Il écrivait dans le Manitoba, Paris-Canada, la Croix de Paris, la Défense de Chicoutimi, le Courrier de Saint-Hyacinthe, le Bulletin de la Canadienne, la Semaine Religieuse de Québec, le Mouvement catholique, l'Indépendance bretonne, les Cloches de Saint-Boniface, et vraisemblablement dans le Trifluvien et l'Univers.

46 MSACR(A), Correspondance, Somerset, Document 204: lettre de Paul Benoît à Adélard Langevin, le 18 juillet 1906.

$47 \operatorname{MSACR}(\mathrm{A})$, Registre des lettres d'Adélard Langevin, vol. I, p. 106: copie d'une attestation d'Adélard Langevin, le 28 février 1898. 
le gérant d'une banque à Winnipeg montrait combien était enviable son crédit, lorsqu'il priait l'archevêque de lui transporter un billet du fondateur; "les prêts de ce genre, ajoutait-il, nous font toujours plaisir ".

L'accession de Langevin au siège archiépiscopal de Saint-Boniface avait marqué le début de rapports très spéciaux entre le chef de l'archidiocèse et son curé aux intérêts multiples. Certes, Benoît en 1890 avait rencontré un archevêque spirituel et enjoué. Mais, devant la défaite confirmée de la minorité dans la question des écoles du Manitoba, celui qui avait dépensé sa longue carrière à préparer toutes les prairies à la civilisation ressemblait peu à l'homme énergique qu'il avait été quelques années auparavant. En effet, Taché avait perdu ses illusions, était abattu et très malade, et même dégoûté par le sentiment que deux hommes publics de ses propres compatriotes l'avaient trahi, cet homme n'était plus l'initiateur de nouveaux combats pour ses aides. Tout différent était son successeur; la présence du fougueux et énergique Langevin devait changer tout cela. En moins de deux ans, ils s'étaient étudiés, évalués et compris mutuellement, pour se trouver une idéologie presque en tous points commune. La devise de l'archevêque, Depositum custodi, indiquait sans équivoque dans quel sens il entendait ramer; et ce mot d'ordre du chef semblait convenir parfaitement à son aide. Il importe de ne pas passer sous silence le fait que les deux hommes avaient des tempéraments dissemblables: à l'archevêque nerveux, touj ours pressé, débordant d'une ardeur venant du cœur, homme d'action, grand bâtisseur, s'opposait le religieux posé, nonchalant, débordant de détermination et de volonté, homme de pensée, grand intellectuel consacré aux œuvres de l'esprit dans la sérénité de son monastère. Ces deux hommes, comme le jour et la nuit, se rejoignaient curieusement au plan des idées.

Dès 1895, Saint-Claude et Saint-Oyend étaient, à leurs érections canoniques en paroisses, confiées aux Chanoines réguliers, à titre de dessertes d'abord. En 1897, les prêtres deviendraient résidants à SaintClaude, leur premier prieuré du groupe canonique de la montagne de Pembina. Benoît faisait construire, la même année, une chapelle dans la partie orientale de la paroisse de Notre-Dame-de-Lourdes, dans un endroit qu'il avait nommé Saint-Oyend, et dont il espérait, par suite $\mathrm{du}$ peuplement et du progrès rapide, un démembrement de la paroisse primitive. Il n'acceptait que deux des quatre fondations que lui proposait son chef cette année-là.

Mais, l'année suivante, les Chanoines réguliers prenaient la charge de Saint-Daniel, pays des Métis au sud de Saint-Claude, autrefois les Îlets de Bois, pour lesquels Benoît avait du reste une prédilection, en vertu de leurs droits historiques si souvent bafoués par les Blancs. De 
plus, en 1898, il acceptait à nouveau, mais non plus simplement à titre provisoire, la paroisse de Saint-Léon, deuxième prieuré. Cette dernière comprenait les missions de Somerset, Altamont, Deerwood, Miami, Manitou, et d'autres; comme Saint-Daniel comportait la charge de Carman.

Des quatre premières fondations qui étaient proprement celles des Chanoines réguliers, Notre-Dame-de-Lourdes et Saint-Claude prospéraient de façon satisfaisante, Saint-Oyend connaissait un départ hésitant, puis périclitait rapidement, et Saint-Martin, l'une des deux paroisses projetées au nord et à l'est de Saint-Claude, restait largement sur papier. La congrégation devait desservir éventuellement Haywood, et parfois Fannystelle, jusqu'aux portes de Winnipeg, où le curé séculier sur son départ aussi bien que certains paroissiens réclamaient les prêtres blancs.

En 1900, Benoît acceptait Saint-Alphonse à titre de troisième prieuré, avec les missions de Rock Lake, Baldur, Mariapolis et Swan Lake. Bruxelles, paroisse largement wallonne, lui était confiée provisoirement en 1899.

Dans les premières années du nouveau siècle, les Chanoines réguliers étaient appelés à Bonne Madone, dans la Saskatchewan, et à Végreville, dans l'Alberta.

En 1905, le supérieur faisait construire une chapelle dans les limites de sa paroisse, sa cinquième fondation, dans un autre endroit qui porterait le nom d'un saint dont il avait rappelé la vie dans ses écrits: saint Lupicin. Les départs y seraient lents, d'autant plus que celle-ci était détruite par un ouragan trois ans plus tard: " Je n'ai pas d'objection, avait écrit l'archevêque de Saint-Boniface, à dédier cette chapelle à St-Lupicin; [sic] mais j'avoue que depuis l'essai de St-Oyend [sic] je n'ai pas la ferme conviction que ces bons saints du Jura veuillent nous aider beaucoup ${ }^{48}$ !"

Il y aurait assurément des commentaires à faire sur le problème des nationalités dans la montagne de Pembina, chaque paroisse tendant à avoir la sienne: Haywood. savoyarde; Saint-Claude, française; SaintDaniel, métisse; Notre-Dame-de-Lourdes, mixte; Saint-Léon, alsacienne et québécoise; Mariapolis, québécoise; Bruxelles, wallonne; Swan Lare et Saint-Alphonse, flamande; Treherne et Rathwell, anglaise.

C'étaient les belles années. la collaboration dans la confiance réciproque. S'ajoutait à cela la faveur de Langevin, et l'expansion de tous côtés, d'autant plus que les Chanoines réguliers étaient mieux

48 MSACR(A), Registre des lettres d'Adélard Langevin, vol. VI, p. 823-824: cripie d'une lettre d'Adélard Langevin à Paul Benoît, le 12 févi ier 1904. 
équipés que le clergé séculier pour fournir un prêtre alsacien aux "Allemands " de Saint-Léon, un flamingant aux gens de Swan Lake et de Saint-Alphonse, un pasteur anglophone aux populations de Rathwell et de Treherne, et ainsi de suite ${ }^{49}$. Aussi n'est-il pas surprenant qu'en moins d'années, le délégué de Gréa au Nouveau Monde se trouvait à la tête de " 16 maisons au Canada ${ }^{50}$ ". Cette phalange était troisième dans l'ordre de préséance, dans l'archidiocèse de Saint-Boniface, après les séculiers et les Oblats. Notre-Dame-de-Lourdes avait cinq prieurés, dans la région, et deux à distance dans l'ouest, et avec eux la collégiale formait le groupe canonique de la montagne de Pembina. Le groupe canonique du Nominingue se développait séparément sous la direction lointaine de dom Benoît.

Mais le recrutement du personnel indigène était très faible. pour ne pas dire inexistant. Les rangs des Chanoines réguliers étaient renfloués périodiquement par des renforts venus de France ${ }^{51}$.

On peut résumer et énoncer ici quelques conclusions générales sur la première partie de l'œuvre de dom Benoît en terre d'Amérique, la colonisation.

Les Chanoines réguliers, en dépit des idées de reconversion qu'avait eu leur supérieur en s'expatriant, n'ont jamais pu faire la moindre percée du côté des populations anglo-protestantes. Ils y ont maintenu la vie catholique sans pouvoir l'étendre.

S'il s'agit d'évaluer l'œuvre de colonisation française de Paul Benoît au Nouveau Monde, force est bien de préciser les divers aspects de cette œuvre. A-t-elle été un succès ?

Pour Notre-Dame-de-Lourdes et Saint-Claude, un succès net, très certainement. Il est manifeste, par ailleurs, que l'œuvre de colonisation de Benoît, dans son ensemble, a été moins importante que celle de Jean Gaire, qui établit quatre paroisses près de la frontière du Manitoba, qui fit de cette auvre la préoccupation constante de toute sa longue carrière nord-américaine, et dont Langevin put écrire: "Dix prêtres

49 Ainsi, au $1^{\text {er }}$ juillet 1900 , la communauté de trente et un, à Notre-Damede-Lourdes, comptait 20 Français, 6 . Canadiens, 1 Suisse, 2 Irlandais, 1 Polonais, et 1. Allemand ": MSACR (A), Documents historiques, Correspondance, juin 1900juillet 1900, Document 51: Paul Benô̂t, Population catholique de Notre-Dame-deLourdes au $1^{\text {er }}$ juillet 1900 , sans date.

50 Félix Klein, $A u$ pays de "La vie intense ", $8^{\mathbf{e}}$ éd., p. $72-73$.

51 T. A. BERNIER, "Les religieux français dans l'Ouest canadien ", dans Le Manitoba, XXXII, 6 (24, décembre 1902), 2. Il y avait, dans l'archidiocèse de Saint-Boniface, en 1902, quarante cinq [sic] chanoines réguliers [sic] de l'Immaculée Conception, presque tous de langue française, dont trente étaient nés en France .. Mais précisément les quinze issus de la population indigène ne persisteraient pas dans leur voie. 
comme l'abbé Gaire [...] réussiraient à fonder un empire catholique et français en ce pays ${ }^{52}$."

Mais avec sa communauté, dom Benoît a pesé puissamment sur le destin de la montagne de Pembina, car ses principales fondations au centre ont servi de maillons à une longue chaîne de population française allant de Fannystelle à Saint-Alphonse.

Quant à la volonté qu'il avait eue de reconquérir l'Ouest à la religion catholique sinon à la culture française, elle n'aboutit même pas à maintenir le statu quo. Au cours de sa carrière dans l'Ouest canadien, en effet, la minorité franco-manitobaine subissait un recul continuel qui devait aboutir, en 1916, à la révocation des quelques lambeaux des droits qui lui restaient comme suite au compromis Laurier-Greenway. Il y a lieu de consiater ici un échec iotal, sans bien sûr déprécier les efforts importants que le Chanoine régulier avait dépensés pour refaire toute cette partie du monde plus conformément à ses vues.

Reste à voir si son cuvre de colonisation, par elle-même, et peu importe l'issue finale dont tous s'accordent à dire qu'elle n'a rien de brillant, représente une conquête valable dans ses limites. Le cadre de cette communication ne permet de donner qu'une seule statistique de comparaison là-dessus: de 271 qu'ils avaient été en 1899, les immigrants vers l'ouest canadien en provenance de la France et de la Belgique pour 1900 n'étaient que 228, alors que l'immigration totale serait de 31.937 individus ${ }^{53}$. Mais 118 seulement s'installaient au Manitoba ! C'est en ce sens qu'on ne s'avance guère en affirmant que Benoît et ses confrères ont conduit plus de colons dans la montagne de Pembina, dans les cinq premières années seulement de leurs établissements, que les deux principaux pays francophones d'Europe n'en fournirent à tout l'Ouest canadien en une seule année!

Il faut bien constater qu'en dépit de sa résolution, au lendemain de l'incendie des constructions ecclésiastiques de Notre-Dame-de-Lourdes en 1891, de se consacrer désormais à l'œuvre de la colonisation, il n'a pas vraiment donné suite à cette velléité. Il n'est jamais retourné en France dans un but de recrutement de colons, ce qui seul aurait constitué une façon vraiment efficace de faire ailleurs ce qu'il avait fait avec succès à Notre-Dame-de-Lourdes et à Saint-Claude. Il n'en avait pas les moyens; au surplus, il avait le cœur et l'esprit ailleurs, surtout à partir de l'accession de Langevin. C'est un demi-succès en soi; c'est

52 Le vice-amiral [Cavelier] DE Cuverville, Le Canada et les intérêts français, p. 70. Bien sûr, Langevin aimait les formules saisissantes; il ne faut peut-être pas prendre celle-ci au pied de la lettre.

53 MSACR (A), Documents historiques, Correspondance, décembre 1900- varia 1900, Document 23: Immigration européenne française \& belge, pour l'année 1900, sans date. 
une demi-faillite par rapport à ce qu'il aurait pu accomplir s'il avait œuvré systématiquement, pendant un quart de siècle, à l'implantation de colonies de culture française dans l'Ouest canadien. L'expérience de Saint-Oyend lui avait vite enseigné que le courant de l'immigration n'aboutissait à rien s'il n'était soutenu par un recrutement aussi efficace que celui qu'il avait mis en œuvre en 1890 .

On n'a, jusqu'ici, exposé sommairement. que le premier et le principal aspect de la carrière nord-américaine de dom Paul Benoît. Le second, c'est à coup sûr l'implantation canonique dans l'ouest, celle des communautés masculine et féminine, que deux voix plus autorisées et plus instruites du sujet sont appelées à tracer d'une main de maître.

Quant à tous les autres aspects, bien nombreux, de cette œuvre. c'est une lourde tâche de les retracer, tant elle a été prolifique. Il ne peut même être question de l'exposer adéquatement. Peut-être, tout au plus, de l'esquisser à grands traits.

D'abord, la question des écoles de Manitoba, la plus épineuse de toutes celles dont Langevin avait hérité en 1895 , le plus pesant de tous les fardeaux, son rocher de Sisyphe. Tout le monde le sait, elle n'a jamais aboutie à la satisfaction de la partie lésée. Elle a même provoqué en 1896 un profond réaménagement politique dans tout le pays. Elle a donné lieu à une abondante littérature, soit d'information, soit de parti-pris. Pour parler comme un Salinger. si on avait cinquante vies pour la retracer jusque dans les détails, elles seraient insuffisantes pour rendre compte de tout ce que cette question a fait couler d'encre. Sait-on qu'il existe trois documents capitaux sur la question aux archives de Saint-Boniface, attestant que Benoît a. le premier, poussé son archevêque hésitant dans la voie que personne ne voulait se résoudre à considérer comme une solution, mais qui éventuellement est devenue une situation de fait partout dans le Manitoba?

Langevin en 1895 avait été déterminé à ne pas reculer, mais d'exiger la restitution intégrale des droits de la minorité. On connaît les longs débats du parlement fédéral en 1896, occasionnés par cette question. les élections qui suivirent, la chute de Tupper. l'accession de Laurier, le compromis Laurier-Greenway repoussé par l'archevêque de Saint-Boniface, la constitution des écoles dites «du régime de Monseigneur» face aux écoles dites "nationales" de Greenway. lesquelles étaient seules subventionnées par la province. On se rappelle la nomination d'un ablégat pontifical sur les instances de Laurier, son rapport au pape, l'encyclique Affari vos de Léon XIII sur la question. en 1897. 
Or l'encyclique, déclarant le compromis Laurier-Greenway imparfait, suggérait néanmoins aux catholiques de ne pas refuser des satisfactions partielles, quitte à continuer de réclamer le reste.

Très tôt, Langevin ayant reçu ce conseil de Rome, ayant accepté " quelque argent » de Laurier pour le maintien de ses écoles archiépiscopales, - manœuvre adroite du premier ministre qui liait les mains de l'archevêque, - se voyant refuser par le délégué apostolique une quête nationale pour ses écoles, et constatant que la minorité catholique de Manitoba s'essoufflait vite à verser une double cotisation, - les argents pour les écoles libres, et les impôts pour les écoles d'État, il était indécis sur ce qu'il y avait de mieux à faire. Sait-on que c'est dom Benoît qui le premier à Notre-Dame-de-Lourdes a appliqué le modus vivendi de 1898 par lequel on acceptait les subventions provinciales, on proclamait les écoles " nationales ", et officiellement neutres ? Il s'était vite rendu compte du fait qu'il pouvait avoir des écoles " nationales" de droit, mais "catholiques» de fait (par la complicité clandestine et affectueuse de sa population en totalité de culture française et de religion catholique). Il avait consenti une concession au niveau des mots, du jour où il avait compris qu'il n'avait besoin d'en faire aucune au niveau des faits: le français, la religion s'y enseignaient librement dans ses écoles, l'État fermant les yeux devant les accrocs faits à la lettre de la loi, l’Église mettant un peu d'eau dans son vin en acceptant la désignation " écoles nationales". Le modus vivendi s'est graduellement étendu aux autres centres catholiques par toute la province, ne causant de difficultés, mais de grandes, que dans les centres mixtes, où la majorité protestante tirait à elle toute la couverture. Il devait subsister jusqu'en 1916.

Cette issue était évoquée par Benoît dans une adresse lue à son archevêque, datée du 23 décembre 1906. $\mathrm{M}^{\mathrm{gr}}$ Langevin a fait des corrections de sa main, a marqué le document "archives", mais a laissé tel quel le passage témoignant du fait que le modus vivendi avait commencé dans les écoles ouvrant sous l'égide de son curé religieux ${ }^{54}$. $\mathrm{Au}$ reste, deux lettres de l'archevêque abondent dans le même sens: le Chanoine régulier lui avait rappelé qu'il y avait loin de la coupe aux lèvres, que tous pouvaient trouver une satisfaction adéquate dans des accommodements de principes, du moment qu'on n'avait pas besoin d'en faire aucune au niveau de la pratique. Mais dom Benoît s'était constitué des paroisses homogènes: françaises et catholiques, où le modus vivendi ne comportait guère d'inconvénients. Il ne semble pas avoir assez tenu compte que dans des centres constitués par des populations moins unies. cet arrangement ne pouvait guère donner satisfaction.

54 MSACR(A), Correspondance, Somerset, Document 209: adresse de Paul Benoît à Adélard Langevin, le 23 décembre 1906. 
Tout allant bien chez lui de ce côté-là, il semble s'être de bonne heure désintéressè des écoles des centres moins fortunés que les siens. Il a continué, bien sûr, à réclamer pour la minorité, mais presque uniquement dans ses écrits, et il ne mettait plus la même urgence dans ses réclamations que du temps où la question scolaire avait été un grand problème à Notre-Dame-de-Lourdes même. Pour lui la question des écoles de Manitoba était réglée.

Dom Benoît a laissé maintes pages sur ce sujet, à tel point qu'un biographe de la région allait jusqu'à le décrire comme "le principal écrivain du côté catholique de la question des écoles [de Manitoba] ", ce qui semble toutefois une appréciation excessive.

On a rappelé déjà la grande place qu'avaient tenue les livres dans la vie de cet intellectuel lorsqu'il vivait auprès de dom Gréa. Il avait beaucoup écrit. Puis, en passant au Nouveau Monde, il était devenu comme le volcan éteint; d'autant plus que, suite à la perte de ses manuscrits, il avait résolu de mettre sa vocation d'écrivain au rebut pour se dévouer à la colonisation de sa patrie adoptive et à sa conversion à la foi catholique.

Il y eut un silence relatif de cinq ans. Avant l'accession de Langevin, il s'était borné à publier deux rapports statistiques, en 1893 et 1894, dans le Manitoba. Mais il avait, comme le lui reprocherait un jour le journal rival, "la démangeaison d'écrire".

Sa résolution de ne plus composer de livres n'avait donc tenu qu'une année: 1892. Dès 1893 et jusqu'en 1896 , à partir de " 5 petits cahiers restés chez un ami, curieux de ces sortes d'études ${ }^{55}$ ", et donc sauvées des flammes, et à partir de ses souvenirs et de "quelques recherches ", il avait rédigé à nouveau La Vie des Clercs dans les Siècles passées. L'ouvrage devait être imprimé de son vivant, mais publié à titre posthume; on s'intéressait peu au Nouveau Monde, disait-il, à " ces sortes de recherches". Mais il s'agissait d'un abrégé; l'ouvrage n'aurait plus huit volumes, mais un seul.

Du temps de Taché également, les deux premiers volumes de La cité antichrétienne au XIX $X^{e}$ siècle, cette première partie intitulée Les erreurs modernes, connaissait une quatrième édition, alors que l'autre partie, intitulée La franc-maçonnerie, n'était rendue qu'à la seconde.

Avec l'arrivée de Langevin, qui l'encourageait, le Chanoine régulier livrait des rapports statistiques, plus nombreux, sur la colonisation de la montagne de Pembina, au Manitoba, à Paris-Canada, à la

55 MSACR(A). Religieux, Chanoines réguliers de l'Immaculée Conception. Document 285: lettre de Paul Benoît à Adélard Langevin, le 22 janvier 1914. 
Semaine Religieuse de Québec, au Bulletin de la Canadienne, pour lequel il était l'un des correspondants accrédités, aux Cloches de SaintBoniface. C'étaient vraiment des modèles du genre: un nombre considérable de chiffres, épars dans ses premiers articles faits d'après les recensements paroissiaux, et qu'on trouvait groupés et comparés dans les années suivantes, étayaient les raisonnements de l'auteur et donnaient à ses travaux une rare valeur documentaire ${ }^{56}$.

C'est vers le tout début du $\mathrm{XX}^{\bullet}$ siècle que l'aspect controverse a occcupé une large place dans la vie de Benoît. Tout cela a commencé, semble-t-il, du jour où la rédaction du Manitoba, cherchant à renflouer son tirage, a pu annoncer un accord intervenu entre lui et elle vraisemblablement à la demande du journal.

Il écrirait de l'apologétique catholique et conservatrice. Plus spécifiquement, il s'en prendrait aux démocrates, aux libéraux, aux esprits forts, aux libres penseurs, aux protestants, aux francs-maçons, aux incrédules, aux impies, aux modernistes, aux socialistes. Il s'agissait de " hâbleurs ", terme fréquent sous la plume de Benoît, de " sectaires ", ces "impies modernes ", qui risquaient de troubler la foi des enfants de l'Église par leurs " déclamations ", leurs " dires ineptes". Comme il ne donnait pas ses sources, à l'inverse de ce qu'il faisait méticuleusement dans ses écrits historiques, pour ses phrases qu'il citait abondamment de ses soi-disant adversaires, il avait beau jeu de mettre sur leurs lèvres, en les interpolant au choix, en les accentuant surtout, toutes les déclarations susceptibles de les faire paraître plus extrêmes qu'elles ne l'étaient. On ne manqua pas de lui reprocher cette façon de procéder, qui exaspérait ses rivaux dans les colonnes de l'Écho de Manitoba. Une deuxième caractéristique, c'était le raisonnement par l'absurde, très fréquent dans ces travaux. En troisième lieu, il s'agissait d'écrits très dogmatiques, faits sur le ton le plus péremptoire; c'était une faiblesse, car si ses conclusions étaient logiques et irréfutables, ses prémisses très catholiques évidentes pour lui ne l'étaient pas du tout pour ceux auxquels il prétendait répondre. Enfin, il y avait une certaine tendance à vilipender ses adversaires, car il ne cherchait pas à attirer et à convaincre des indécis, mais à repousser et culbuter des rivaux, qu'il était peut-être

56 Paul Benoît, "La paroisse canadienne-française ", dans Revue catholique des institutions et du droit, 37 ( $2^{e}$ semestre 1906), p. 215-252.

Il était bien permis à Benoît de croire que cla race canadienne-française compter[ait], au bout d'un siècle, dans l'Amérique du Nord, 15 ou 20 millions d'habitants ».

D'une part, il avait constaté que l'excédent de 294 naissances à Notre-Dame-deLourdes était * précisément * ce qu'il devait être * pour l'augmentation du double de la population en vingt ans". D'autre part, il constatait " dans la multitude des colonies de langue française, établie depuis trente ans dans l'Ouest canadien "la même proportion". La conclusion était donc logique.

Mais non irréfutable; car Benoît ne tenait aucun compte des impondérables, lui qui connaissait et répétait cet adage latin: l'homme propose et Dieu dispose. 
plus facile d'ensevelir sous le mépris que de séduire soit par l'argumentation logique, soit par la puissance de l'exemple.

Faut-il souligner ici la participation reptilienne dans les écrits de dom Benoît? Si les animaux ont maintes fois peuplé ses débats, il a néanmoins eu une sainte horreur en même temps qu'une prédilection certaine pour tous ceux qui rampaient. Il faut sans doute voir là une figuration de celui par lequel, primitivement, le mal était entré dans le monde ${ }^{57}$.

Il faut bien mentionner que toute sa polémique n'était pas de ton virulent, loin de là. Benoît goûtait beaucoup les remontrances enrobées dans l'humour.

Très tôt, le Mouvement catholique des Trois-Rivières s'intéressait à ses articles parus dans le Manitoba, comme plus tard, la Semaine Religieuse de Québec relèverait ses écrits parus dans le Mouvement catholique. Certains de ses articles paraîtraient dans jusqu'à quatre revues ou journaux. Tous ne goûtaient pas ses attaques faites visière levée et sans aucun quartier. Son ami, le sénateur T. A. Bernier, le prévenait que certains de ses écrits, "ces grands coups d'épée", risquaient " de jeter de l'huile sur le feu des guerres de races, de fomenter les préjugés ${ }^{58}$ ". N'importe, il avait la plume facile, un immense intérêt pour les grands courants d'idées de son temps, et une surabondance d'énergie à dépenser. Il multipliait les charges.

Comme le Mouvement catholique s'alignait sur la plus stricte orthodoxie catholique, "les yeux fixés sur Rome », comme elle l'exprimait elle-même, très tôt dom Benoît s'était mis à écrire avec allégresse dans cette revue qu'il préférait à toutes les autres, sauf la Civiltá cattolica. Dans l'année 1899, il livrait à cette revue seize articles, en vingt-quatre tranches, visant le libéralisme catholique surtout, dans ses multiples aspects, et non seulement du point de vue théorique. Déjà, à l'orée de l'année 1900, sa troisième d'existence, la direction du Mouvement catholique le remerciait pour ses écrits, en signalant qu'il était devenu avec le Français $\mathrm{M}^{\mathrm{gr}}$ Justin Fèvre l'un de ses « deux collaborateurs les plus réguliers ${ }^{59}$ ".

Allégrement, la Semaine Religieuse de Québec avait entrepris la reproduction de la série de six tranches de L'anglomanie au Canada, toujours tirées du Mouvement catholique.

57 Il comparaît volontiers les "sectaires" à des reptiles \& qui ne savent que souiller de leur bave les sentiers où ils passent ", évoquant à plaisir a leurs petites têtes méchantes »: Paul Benoît, "L'obscurantisme du soleil ", dans Le Manitoba, XXVII, 40 (24 août 1898), 2.

58 ASJ (CF), Dossier Paul Benoît-T. A. Bernier. Document 5316-11 : transcription dactylographiée du brouillon d'une lettre de T. A. Bernier à Paul Benoît, le 29 mars 1899. Gracieuseté du père Léon Pouliot, s.j.

59 . La nouvelle année $\%$, dans Le Mouvement catholique, V. 1 (1900). 2-4. 
Pour dom Benoît, l'empire auquel on était rattaché, écrivait-il dans L'anglomanie au Canada, n'étant pas nécessairement bâti pour toujours, il n'était pas interdit de songer que le sort pût se retourner contre l'Angleterre, " la grande corruptrice de la terre, l'injuste dominatrice, la reine de malheur ". Certes, il eût désiré que l'Angleterre pût continuer "d'être visitée par les rosées du ciel et de recevoir la graisse de la terre ", mais il évoquait avec un plaisir sûr les événements en puissance sur lesquels il pouvait prétendre n'avoir aucun contrôle, mais que l'objectivité lui commandait d'envisager:

Or, et c'est là que nous en voulons venir, les abaissements de la race anglaise peuvent rendre les anglomanes du Canada plus modestes. Serait-il possible, lorsque tous les peuples rompront le joug de la grande dominatrice, que les Canadiens-français continuassent à subir l'oppression? Les chances de la lutte, si longtemps favorables aux oppresseurs, se retrouveront [retourneront?] en faveur des victimes. "Levez vos yeux, Canadiens-français, parce que votre rédemption est proche. Vous, battus et conquis par l'Angleterre, toujours haîs et resserrés davantage par la race ennemie de la vôtre, dont les enfants sont forcés de parler la langue des oppresseurs dans les écoles des Etats-Unis et du Manitoba, vous verrez enfin l'astre de la liberté se lever pour vous et vos droits pleinement respectés par ceux qui les ont violés si longtemps 60 .

Mais livrée par tranches, cette publication s'était éternisée. La Guerre anglo-boer avait commencé, avec de grands revers anglais. Le Soleil de Québec accusait l'auteur d'avoir voulu jeter " le cri de révolte ouverte ». Il s'en suivait un tollé général d'un bout à l'autre du pays ${ }^{61}$. Le Journal de Montréal l'accusait d'avoir livré " un écrit faux, injuste, déloyal et séditieux ${ }^{62}$ ". A Winnipeg, on allait jusqu'à parler de trahison; par implication, on demandait la punition du coupable.

Loin de reculer devant les protestations, et la rumeur d'une intervention de la délégation apostolique dans cette affaire, l'auteur était la sérénité même:

Que je suis en paix et que j'y demeurerais bien profondément, quand même mille écrivains parleraient plus violemment contre moi que le Journal, [...]

[...] Mon Dieu! que ce monde anglais descend de plus en plus dans mon estime à mesure que j'avance! J'avais été nourri dans les idées de Montalembert sur l'Angleterre; j'en suis bien revenu depuis que je suis au Canada 63 .

Le Chanoine régulier songeait même à revenir à la charge: « $[\ldots]$ : quand on a dit la vérité, on doit la soutenir, si elle est attaquée ${ }^{64}$. Mais, à la demande de l'archevêque, il remettait "l'épée au fourreau ".

60 Paul Benôit, L'anglomanie au Canada, p. 59.

61 Deux journaux anglais sur trois à Winnipeg commentaient l'affaire. Le Manitoba évoquait al'émoi qui [venait] de faire tressaillir le pays ».

62 . Une grande colère ", dans Le Journal, 1, 23 (15 janvier 1900), 4

63 MSACR(A), Documents historiques, Correspondance, varia 1899-janvier 1900, Document 35: lettre de Paul Benoît à Adélard Langevin, le 23 janvier 1900.

$64 \operatorname{MSACR}(\mathrm{A})$, Documents historiques, Correspondance, varia 1899-janvier 1900, Document 34: lettre de Paul Benoît à Adélard Langevin, le 30 janvier 1900. 
Il semble que le mot de la fin, publiquement exprimé là-dessus, doive appartenir au journal Les Débats, qui est allé droit au but et a clairement résumé l'incident dans son tout premier paragraphe:

Il est bien malheureux que La Semaine Religieuse de Québec ait donné lieu à ce concert de cris et de protestations qui ont rempli notre presse, durant toute la semaine dernière; ait donné raison aux journaux anglais de dire tout le mal possible du clergé canadien, et aux journaux de langue française, l'occasion de répéter leur sot aplatissement ${ }^{65}$.

L'anglomanie au Canada paraîtrait quand même en brochure, sans soulever aucune protestation. Quelques petits changements n'ayant pu y être apportés, parce qu'elle était déjà imprimée et brochée, Langevin déclarait ne pouvoir en approuver publiquement la publication. Les deux hommes s'étaient compris. Langevin regarderait de l'autre côté; le Chanoine régulier ferait paraître sa brochure sans approbation publique. Mais avec l'absolution de l'archevêque.

Enfin, du côté des périodiques, les écrits du curé de Notre-Damede-Lourdes ont porté sur des thèmes divers: la défense de la langue française partout où elle s'était implantée ${ }^{66}$; la défense de l'immigration française au Manitoba ${ }^{67}$; à titre de grand partisan de la diversification agricole, sur l'apiculture; et sur d'autres sujets encore. Un article, sur cette dernière question, après avoir relaté la bonne et la mauvaise fortune du rucher des Chanoines réguliers (29 ruches) pour l'année 1908 , et étalé nombre de calculs comparatifs très précis, tirait cette conclusion bien étayée: "Beaucoup de cultivateurs ont moins de revenu avec 100 acres en culture ${ }^{68}$." L'intérêt du curé prolifique se portait de tous côtés.

L'anglomanie au Canada, paru par livraisons dans deux revues, puis séparément en brochure, devait faire partie d'un ouvrage beaucoup plus étendu, sous le titre Le libéralisme contemporain, principalement au

65 Enry D'Eus, \& Echos , dans Les Débats, 1, 7 ( 14 janvier 1900), 1.

66 Ainsi, en 1904, avait-il fait une commande, en français, à un fournisseur d'église de Hamilton. En réponse, on l'avait prié d'écrire sa lettre en anglais. L'effet avait été de renforcer sa détermination. Il s'était, comme toujours, montré décidé à ne pas reculer: Mon bon ami, je ne ferai plus aucune commande à votre maison, jusqu'à ce que j'aie appris que vous avez un employé, sachant parler et écrire le français. Je vais de plus prier tous les supérieurs de nos maisons religieuses d'adopter la même ligne de conduite.s Paul Benoît, "La langue française marche de pair avec la langue anglaise", dans Le Manitoba, XXXIII, 26 (11 mai 1904), 2; reproduit, "Parlons Français", dans Le Courrier de SaintHyacinthe, 50, 53 (18 mai 1904), 1.

67 Apprenant un jour qu'Alfred Kleczkowski, le consul général de France à Montréal, s'était élevé contre cette immigration, dom Bennît était intervenu auprès de lui publiquement par une lettre de protestation insérée dans Le Manitoba; mais aussi, secrètement, auprès du Quay d'Orsay. Paul BEnoît, "Protestation", dans Le Manitoba, XXII, 11 (2 février 1898), 1.

68 Paul Benô̂t, a L'apiculture dans la montagne de Pembina durant l'été de 1908 », dans Les Cloches de Saint-Boniface, 8, 5 ( $1^{\mathrm{er}}$ mars 1909), 61-63. 
Canada et aux États.Unis. L'archevêque de Saint-Boniface venant à soumettre quelques articles de cet ouvrage à l'approbation du délégué apostolique, ce dernier, pour qui dom Benoît était peut-être devenu suspect avec les protestations soulevées par ses écrits, en profitait pour en défendre la publication d'une partie, et pour mettre en doute la sagesse de publier l'ouvrage dans son ensemble, lors de la trève entre l'État et l'Église qui avait suivi le modus vivendi de 1898. La défense expresse de publier ne portait que sur un article préconisant la convocation d'un concile plénier pour lutter contre l'envahissement du libéralisme, de tout temps la cible préférée du curé intellectuel; quant au reste de l'ouvrage, le délégué apostolique le voyait d'un mauvais œil. Pendant deux ans, malgré les supplications de Benoît, Langevin, lui-même mal coté auprès du représentant du pape, - ne voulut pas lui accorder une lettre d'approbation; l'auteur ne croyait pas devoir s'en passer. On décida d'attendre l'accession de Ignis ardens, le prochain pape suivant les prophéties de saint Malachie. A l'automne de 1902, il se revisa et accorda l'autorisation. Toutefois, à ce moment-là, il semble que Benoît ait eu quelque difficulté du côté de l'éditeur, sans doute, de sorte qu'on perdait la trace de ce manuscrit dans les archives à partir du 17 décembre $1902{ }^{69}$. C'était un ouvrage mort-né.

Par contre, en 1897, $\mathbf{M}^{\mathrm{gr}}$ Langevin avait approché dom Benoît désirant lui confier la préparation de la biographie de son prédécesseur sur le siège de Saint-Boniface. La demande n'avait eu aucune suite. Il était revenu à la charge le $1^{\text {er }}$ août $1900^{70}$. Le même mois, dom Benoît s'était mis à l'œuvre. L'archevêque espérait que l'ouvrage serait prêt en août de l'année suivante.

Mais au printemps de 1902, on avait déjà sept mois de retard sur l'échéance, et il était prévu qu'il s'agirait d'un ouvrage comprenant " 2 volumes d'environ 400 pages chacun ». En août 1903, on prévoyait un contrat avec le libraire pour 3,000 exemplaires en deux volumes de 400 pages chacun, "pour la somme de $\$ 1,785$ ». En novembre, les dépenses passaient jusqu’à $\$ 2,135$. La rédaction de dom Benoît prenait fin vers le même mois. Le tirage aurait été complété vers le 31 mai 1905: on avait presque quatre ans, en fin de compte, de retard sur l'échéance. Dom Benoît s'écriait: "De mon côté, c'est fini. Mais, le $1^{\text {nr }}$ vol. plus de 600 pages, le $2^{\circ} 930$ ! J'aurais voulu l'édition d'un tiers plus compacte; je crains de ruiner Votre Grandeur pour le papier. » Et la même année, l'archevêque avouait: « La Vie de $\mathrm{M}^{\mathrm{gr}}$ Taché se vend peu, et $\mathrm{M}$. Beauchemin ajoute compte sur compte aux $\$ 7,000$

69 MSACR(A), Registre des lettres d'Adélard Langevin, vol. V, p. 347-349: copie d'une lettre d'Adélard Langevin à Paul Benoît, le 17 décembre 1902.

$70 \operatorname{MSACR}(A)$, Registre des lettres d'Adélard Langevin, vol. II, p. 263-265: copie d'une lettre d'Adélard Langevin à Paul Benoît, le $1^{\text {er }}$ août 1900. 
piastres [sic] déjà dépensées ! C'est égal: l'œuvre est excellente et elle vaut cent fois plus!"

Il n'avait pas du tout échappé à Langevin que Benoît avait "fait joliment l'histoire de 50 ans dans la Vie de $\mathbf{M}^{\text {gr }}$ Taché ", à tel point qu'il aurait alors voulu que le juge L.-A. Prud'homme écrivit l'histoire des débuts du pays, puis un autre, - dom Benoît "s'il le voulait " - - une vie de Provencher, les trois ouvrages constituant alors une histoire depuis les débuts jusqu'à son propre épiscopat.

L'énorme Vie de $M^{g r}$ Taché, - énorme malgré la suppression de l'équivalent de deux chapitres et demi, sur la demande faite sans succès par $M^{g r}$ Taché pour avoir un coadjuteur et sur les interventions du même prélat contre la division du diocèse de $\mathrm{M}^{\mathrm{gr}}$ Laflèche, ainsi que d'autres questions, - pouvait bien ne soulever aucune récrimination. Dieu sait que les conseils n'avaient pas manqué de pleuvoir sur son auteur. L'archevêque allait jusqu'à écrire au publiciste Léopold Leau, à Paris: "P.S. Je vous envoie les deux volumes de la "Vie de $\mathrm{M}^{\mathrm{gr}}$ Taché » écrite par Dom Benoît, à ma demande, sous ma direction, et après révision $[s i c]$ de chaque page que je pourrais signer ${ }^{71}$."

Cet ouvrage ne semble nullement avoir été un succès commercial, bien que dom Benoît avait abdiqué les droits d'auteur en faveur de la future construction de la cathédrale de Saint-Boniface: "plus de 2,000 blancs de souscription " ne rapportaient que près de 500 commandes. Au contraire, l'archevêque intervenait encore auprès de Beauchemin pour qu'il en pressât l'écoulement. Dix ans après que Benoît eut posé sa plume, on le vendait encore "à prix très réduit ».

Par contre, la documentation y était si copieuse que plusieurs des successeurs de cet écrivain y ont puisé libéralement: on en nommerait aisément plus d'une douzaine, y compris W. L. Morton et Arthur Savaète.

En peu d'années après 1895, sa haute science avait fait de Benoît un conseiller écouté de Langevin. De 1896 à 1906 à peu près, le religieux était auprès de l'archevêque comme une espèce d'Agrippa auprès d'Auguste. La confiance de Langevin dans son curé à la robe blanche connaissait alors son apogée. Langevin lui faisait prêcher des retraites au clergé, lui demandait un travail "sur l'arrangement LaurierGreenway », un "projet de sermon " sur l'évêque dans l'Église universelle et dans l'église particulière, un brouillon de supplique pour demander la canonisation de Jeanne d'Arc, son avis sur la possibilité en droit canon de révoquer une fondation perpétuelle faite par clause testamen. taire, lui confiait un document confidentiel aux évêques, sur la question des écoles de Manitoba, à titre, ajoutait-il, de "Cyrénéen".

$71 \operatorname{MSACR}(\mathrm{A})$, Registre des lettres d'Adélard Langevin, vol. XI, p. 727-730: copie d'une lettre d'Ádélard Langevin à Léopold Leau, le 13 septembre 1903. 
A une grave maladie du Chanoine régulier en 1901, l'archevêque écrivait: "Hélas! ce cher Dom Benoît [sic] a failli nous quitter pour le ciel et je ne suis pas encore rassuré sur sa guérison. Quelle perte énorme ce serait pour mon diocèse [sic] ${ }^{72}$ ! " Après sa guérison, il le poussera à écrire dans la Nouvelle-France, une revue de Québec, et dans les Cloches de Saint-Boniface. Son aide par contre poussa l'archevêque à écrire un mot d'encouragement au prétendant en France, lui collectionna des livres, et le pressa à intervenir dans maintes questions politico-religieuses.

Le 29 mai 1902, l'archevêque notait, à l'arrivée de dom Benoît à l'archevêché, dans son journal:

Grande joie /

Quel homme précieux ${ }^{73}$.

En 1907 survenaient des transformations au sein de sa congrégation, dans le sens d'une modernisation. Le fondateur, dom Gréa, était mis à l'écart. Dom Benoît, en homme très volontaire, peut-être trop volontaire, avait tout de suite pris parti, et, totalement axé sur le passé, il précisait, pour le cas où l'on ne reviendrait pas sur cette question, “ j'entrerai dans un deuil qui ne finira qu'à ma mort ${ }^{74}$ ". Ces mots résument à peu près ses dernières années.

Incapable de mettre la moindre goutte d'eau dans son vin, de sacrifier soit des aspects importants de l'œuvre canonique, soit même des accessoires, il était révoqué en 1910. Il devait passer ses cinq dernières années à la retraite à Saint-Léon, dans la prière, mais aussi, homme très actif, dans les études et, on le devine, la rédaction. C'est là vraisemblablement qu'il acheva une Vie de dom Gréa et qu'il rédigea une biographie de religieuse, toutes deux inédites. Il collaborait, sous un quatrième pseudonyme, Paul Blondel, ou sous son nom véritable, à des revues québecoises. Parallèlement, il menait la lutte pour un retour vers le passé et le rétablissement des aspects primitifs de sa congrégation. En 1913, il se sécularisait... pour mieux continuer la lutte de l'extérieur. "Mon cœur est là », disait-il de Notre-Dame-de-Lourdes.

A la fin, en 1915, il se rendait en Europe encore pour intervenir en faveur de la restauration des règles primitives avant de retourner à SaintLéon. A Saint-Boniface, il avait une entrevue avec son archevêque, recevait de lui un don par lequel celui-ci lui reconnaissait une fois de plus ses

72 MSACR(A), Registre des lettres d'Adélard Langevin, vol. III, p. 423-424: copie d'une lettre d'Adélard Langevin à $P$. Boucher de la Bruère, sans date [vers le 5 mai 1901$]$.

73 MSACR(A), Sections des brochures, Journal personnel [de Langevin], 1902: entrée du 29 mai 1902.

i4 MSACR(A), Religieux, Chanoines réguliers de l'Immaculée Conception, Document 167: lettre de Paul Benoît à Adélard Langevin, le 15 décembre 1908. 
états de service. De Saint-John, au Nouveau-Brunswick, il envoyait à Québec un article sur le rétablissement du chapitre cathédral de la vieille cité. Mais c'était le chant du cygne. Son archevêque préféré, qui se sentait en pleine forme au printemps, mourait dans l'été. Le voyage de "Paul Benoît, ptre ", n'avait encore obtenu aucun des résultats qu'il en escomptait, qu'il mourait à Saint-Chamond, patrie de Ravachol, en F'rance. Faut-il voir là un symbole: car Ravachol, leurré par «les erreurs modernes ", avait péri pour ses idées?

Voilà, en gros, l'exposé de la carrière nord-américaine de Paul Benoît. On n'a pas facilement conscience de l'énorme activité qu'il a déployée, parce que, comme le disait Pierre Gaxotte: "Une des infirmités de l'histoire est de raconter, à la suite, des événements qui se produisent en même temps.»

Le mot de la fin appartient à A.-G. Morice, qui vécut ici autrefois, lui aussi Français, lui aussi écrivain prolifique: pour lui, dom Paul Benoît a été "sans contredit l'esprit le plus philosophique, le penseur le plus profond et le travailleur le plus infatigable que l'Ouest canadien ait jamais $\mathrm{vu}^{75}$ 》.

Maurice DUPASQuIER, B.A., M.A.. D.E.S. p. 125.

75 A.G. Morice, Histoire de l'Eglise catholique dans l'Ouest canadien, IV, 